International Journal of Biology, Pharmacy and Allied Sciences (IJBPAS) 'A Bridge Betuen Caboratory and QRender'

WwW.ibpas.com

\title{
IMPORTANCE OF PHYSICAL ACTIVITY AMONG STUDENT POPULATION DURING LOCKDOWN - A QUESTIONNAIRE BASED STUDY
}

\author{
SHREEJHA M.V ${ }^{1}$, ABILASHA. ${ }^{2^{*}}$ AND KAVITHA.S ${ }^{3}$ \\ 1: Saveetha Dental College and Hospitals, Saveetha Institute of Medical and Technical Sciences, \\ Saveetha University, Chennai
}

2: Reader, Department of Oral Pathology, Saveetha Dental College and Hospitals, Saveetha Institute of Medical and Technical Sciences, Saveetha University, Chennai

3: Lecturer, Department of Biochemistry, Saveetha Dental College and Hospitals, Saveetha Institute of Medical and Technical Sciences, Saveetha University

*Corresponding Author: E Mail: Dr. Ganesh Lakshmanan: abilasha@saveetha.com

Received 19 ${ }^{\text {th }}$ March 2021; Revised 25 ${ }^{\text {th }}$ April. 2021; Accepted 20 ${ }^{\text {th }}$ May 2021; Available online $1^{\text {st }}$ Aug. 2021 https://doi.org/10.31032/IJBPAS/2021/10.8.1050

\section{ABSTRACT}

Physical activity is important for weight management, social interaction, and maintaining good health. Decreased physical activity and increase in sedentary behaviour is generally observed during adulthood and college life due to the increase in time invested to fulfil the academic requirement. The purpose of this study is to determine the importance of physical activity among the student population during the lockdown. The study is aimed to determine the pattern of student's physical activity during lockdown days. A cross sectional study was conducted among college students (100 students). Data was collected on an online survey (50.5\% Male, 49.5\% Female). Questionnaire consisted of 20 questions which were circulated through google forms. Responses were collected and transferred to google sheets. Data analysis was by SPSS Software. In this study $45 \%$ of the male and $55 \%$ of the female has been participated, Current profile of the participants are UG aout $42 \%$ and PG students $11 \%$, other students by $45 \%$ in the study, The $42 \%$ of the students could rate good about their fitness level during this lockdown, The $55 \%$ of the participants rate their overall physical activity in the lockdown was somewhat active. The $46 \%$ of the participants spend less than $50 \%$ for their physical activity during this lockdown. Awareness and knowledge about the importance of physical activity was above average and the study can be extended to a larger population.

Keywords: Awareness; Survey; Importance; Physical activity; Lockdown; Students 


\section{INTRODUCTION}

Regular physical activity always has a positive effect on health to avoid the risk of developing disease. Physical activity, and physical fitness, giving a positive impact for the students to concentrate and prevent from various diseases. Physical activity also helps in developing self confidence, self esteem and decrease in stress, anxiety, depression etc. [1]. A meta analysis of physical activity by previous students regarding physical activity college students found that approximately $40-50 \%$ were inactive. Exercise plays a role in it to maintain and develop physical fitness [2]. As per today's lifestyle, quality life has been improved where the students and their parents pay more attention to their personal health, personal development [3]. Due to this current situation of lockdown, physical activity plays a major role to make them brisk and active to carry on their academic activities with efficiency. Conventionally sports is a form of physical activity such as aerobics, running or gym have been focused on physical activity but household work gardening work were not traditionally considered as a physical activity an alternative approach is to be taken which is contextual, social, economic factors which influence in the participation of physical activity qualitative methods offer this in depth insights into individual students which they will get a experience and motivated to do physical activity $[4,5]$. Physical activity and a proper recommended healthy diet helps to reverse the increased prevalence of obesity among the students and children [6]. Numerous research activities were conducted by our team which helps the students and faculty to remain active during their tenure of college education which helps in improving the knowledge not only for the students but also for the general population regarding awareness about various dental aids and oral diseases [7-20]. Apart from routine tests and examinations, many diagnostic research studies were also conducted which also aids keeping the students active both physically and mentally [21]. The aim of the study is to educate students and assess their knowledge and awareness about the importance of physical activity which plays a major role in the mental and physical well being of an individual.

\section{MATERIALS AND METHODS}

A cross sectional study was conducted among students from various schools and colleges. A total of 100 students have been randomly enrolled in this survey through online google forms. A validated Questionnaire consisting of 20 closed ended questions was distributed among the students to assess their knowledge, attitude, 
awareness on the importance of physical activity among students during this lockdown. The data was obtained using google form, tabulated in excel result has been analysed by SPSS Software, Association analysis was done by chi square test using SPSS software

\section{RESULTS AND DISCUSSION}

The responses were obtained from 100 participants and tabulated. In our study Figure 1 explains $49.5 \%$ Female and $50.5 \%$ of Male have participated. In the study Figure 2 explains $46 \%$ of $\mathrm{UG}$ Students $10 \%$ of PG Students, $44 \%$ others as their current profile. The study Figure 3 explains $57 \%$ students would rate their overall physical activity is good. 19\% of the students were not very active during this lockdown. In this study Figure 4 explains $43 \%$ of students fitness level was good during this lockdown $25 \%$ of students, fitness were fair among this lockdown, $18 \%$ of the students felt poor about their fitness level during the lockdown .In the study Figure 5 explains $75 \%$ student felt physical activity enhanced their quality of life $15 \%$ student felt No. In this the Figure 6 explains 92\% students felt physical activity is important during this lockdown. $7 \%$ students answered no. Figure 7 explains $47 \%$ students spent less than $50 \%$ of their time for their physical activity, 31\% students spent $50 \%$ time for their physical activity, $17 \%$ students spent $75 \%$ of their time for physical activity. In this study Figure 8 explains $44 \%$ of the students did physical exercise during this lockdown, 14\% students performed Yoga during this lockdown, $38 \%$ of the students prefer other physical activities during this lockdown. Figure 9 explains $40 \%$ of the students felt anxiety (or) depression during this lockdown $42 \%$ of the students felt no. Figure 10 explains $63 \%$ students knew the cause of lack of physical activity, 30\% students did not know the cause for the physical activity. In this study Figure 11 explains $36 \%$ students say obesity is the cause for the lack of physical activity $8 \%$ students say blood pressure is the cause for lack of physical activity $9 \%$ say high cholesterol is the lack of physical activity $47 \%$ students say all the above will cause due to the lack of physical activity. In this study Figure 12 explains $17 \%$ students says when body is inactive conditions it cause Metabolism effect, $15 \%$ students say lose muscle strength, $10 \%$ students say bone may get weaker $58 \%$ students says all these will be affected when body is in inactive conditions. In this study Figure 13 explains $49 \%$ student spend household work as another way physical activity $22 \%$ student will spend on playing, 105 student will spend on gardening, 19\% will spend on 
other way. In this $79 \%$ In this study Figure 14 use stair to climb stairs at house, college, $14 \%$ students use lift to climb the stairs. In this Figure 15 36\% student spend less than $50 \%$ time on watching $\mathrm{TV}$ or computer, $24 \%$ spend $75 \%$ of their time and $6 \%$ spend $100 \%$ of their time on watching $\mathrm{TV}$ or computer during their lockdown. In this study Figure 16 explains $67 \%$ of the students spend $15-45$ minutes exercise for regular and good health $14 \%$ of students spend 10-15 minutes, 9\% spend less than 10 minutes. Figure 17 explains $9 \%$ participants spend less than $10 \%, 10 \%$ of the participants spend more than an hour, $13 \%$ of the participants spend $10-15$ minutes, $67 \%$ of the participants spend 15 45 minutes to gain good physical health.

Figure 18 explains the activities suggested by the participants during their lockdown times.

Association of the gender with the various parameters affecting physical activity was analysed using chi-square test and depicted in the graphs (Figure 19-25) Most of the association graphs show that there is not much of a difference in the physical activity practiced by male and females.

Previous studies show that the author said lack of physical activity in children leads to cardiovascular problems, weakness of bones, obesity etc. The author advises 60 min of physical activity everybody can help in a healthier life [22]. In this article the author explains 0.69 - 0.43 students affects due to CVS problem due to inadequate of physical activity [23] The author says when there is a regular vigorous physical activity by students they will improve in the strengthening of their body [24]. The author in this study said physical activity was related to greater cognitive perform in early adolescence but not very active in their college or working etc. [25]. Due to lack of physical activity 3.2\% students felt a lack in self efficiency [26]. Another study revealed that students who present high prevalence rates of body image dissatisfaction, developed eating disorders, depression, low self esteem and negative quality of life perception [27]. 


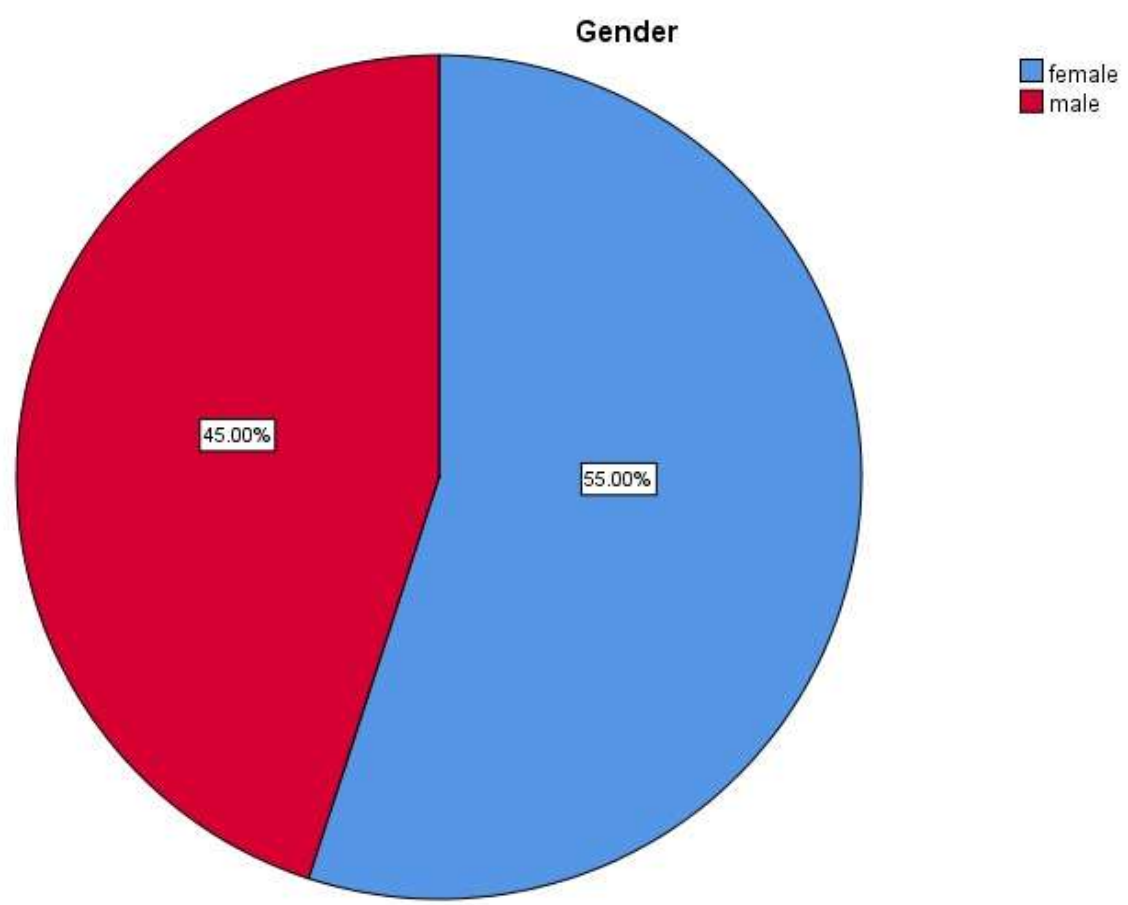

Figure 1: Shows the distribution of the gender among the study population. It shows the Gender scale of the responders where $45 \%$ Male and $55 \%$ of the Female participants. Blue indicates male and red indicates female

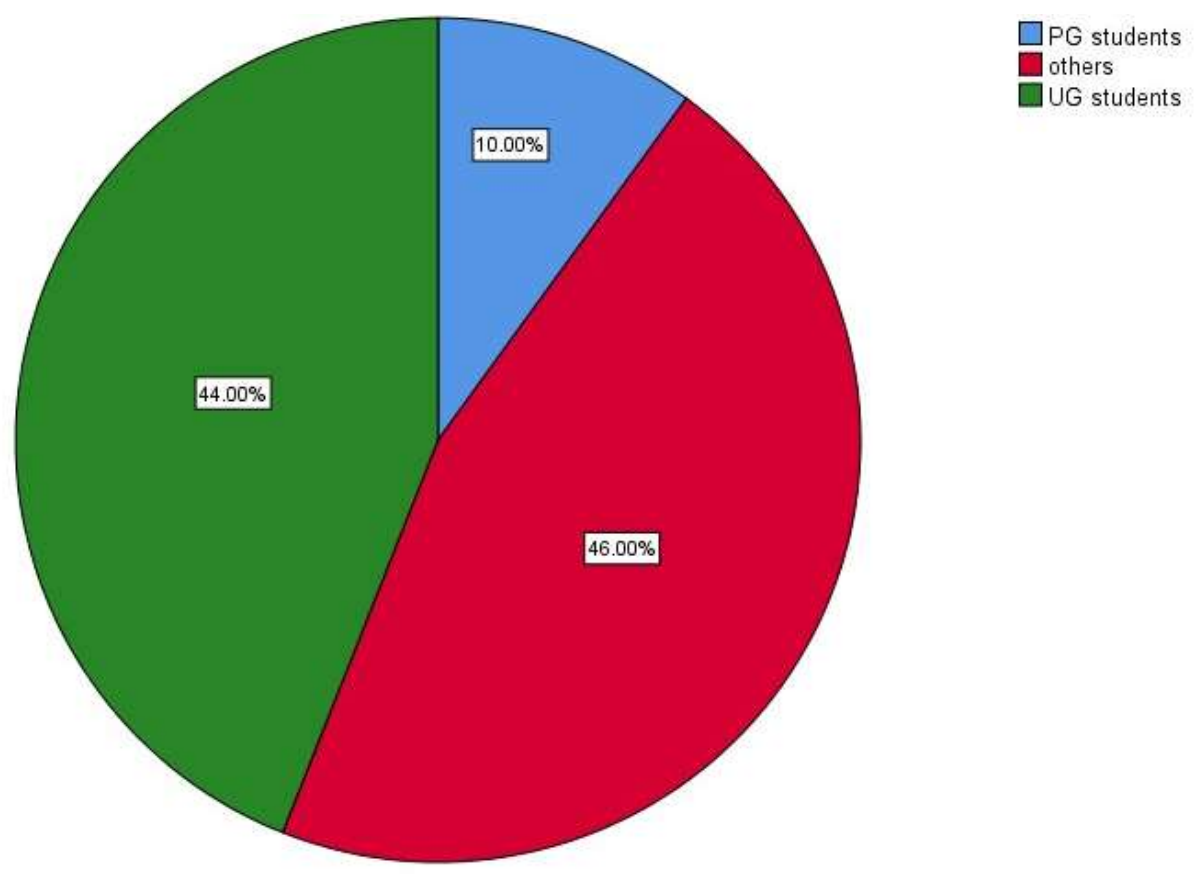

Figure 2: Shows the distribution of participant profiles. $44 \%$ of the UG students and $10 \%$ of the PG students, $46 \%$ of other students,green indicates UG students, blue indicates PG students and red indicates others. 


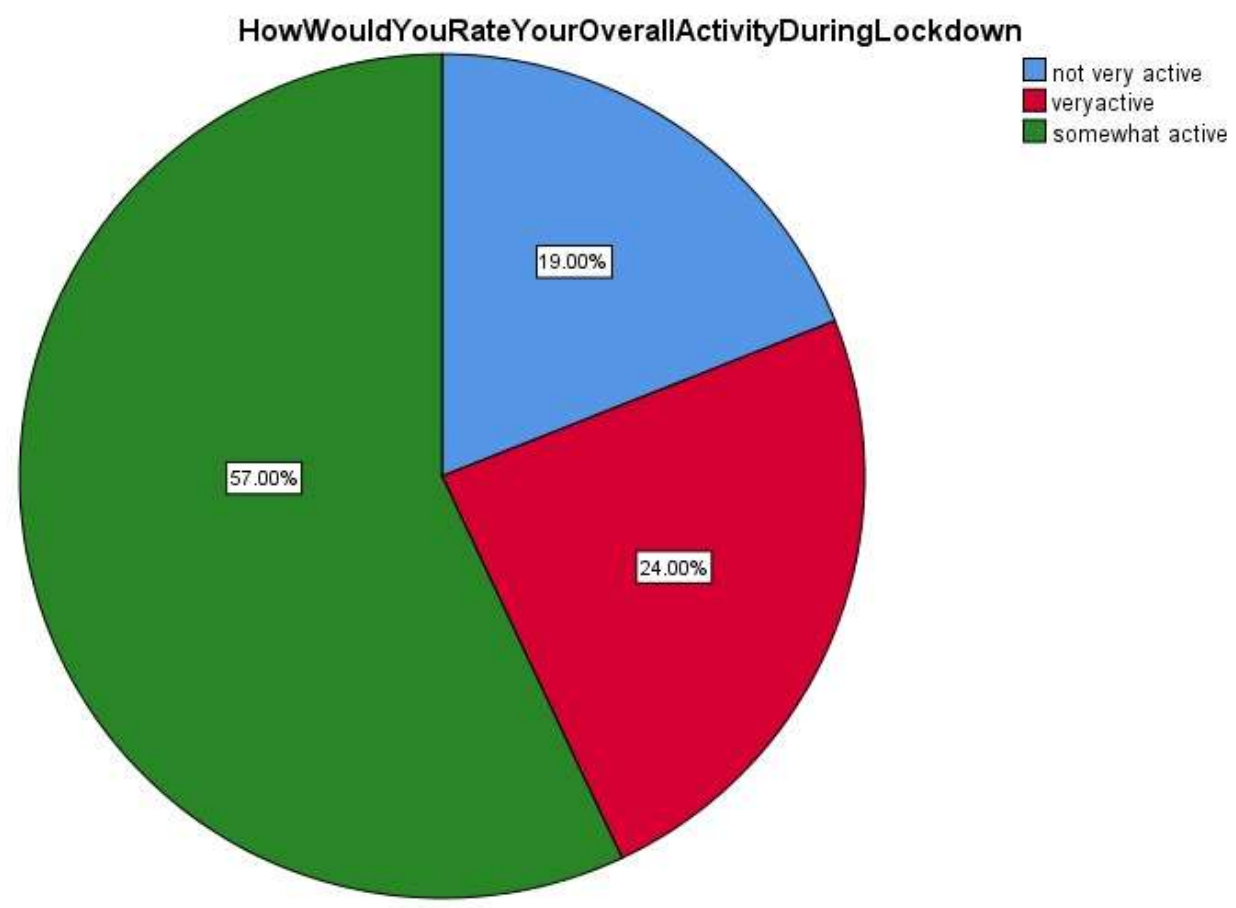

Fig 3: Shows the response of the amount of physical activity among the participants during lockdown. $24 \%$ participants were very active, $19 \%$ of the participants were not very active, $57 \%$ of the participants are somewhat active. Red indicates very active blue indicates not very active and green indicates somewhat active

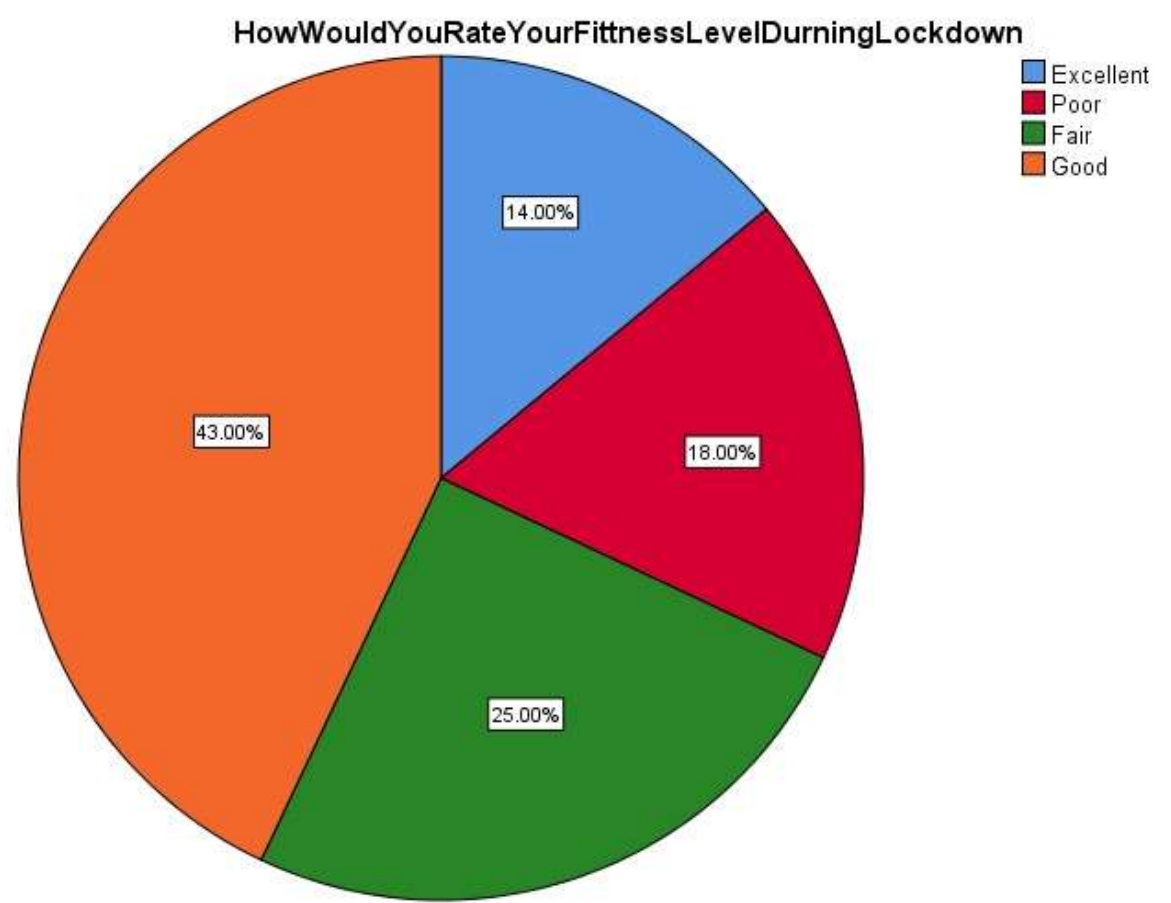

Fig 4: Shows the response regarding fitness level among participants during lockdown period.14\% participants' fitness was Excellent, $43 \%$ of the participants fitness was good, $25 \%$ was fair and $18 \%$ if the participants fitness was poor. Blue indicates excellent, red indicates poor, green indicates fair and orange indicates good 


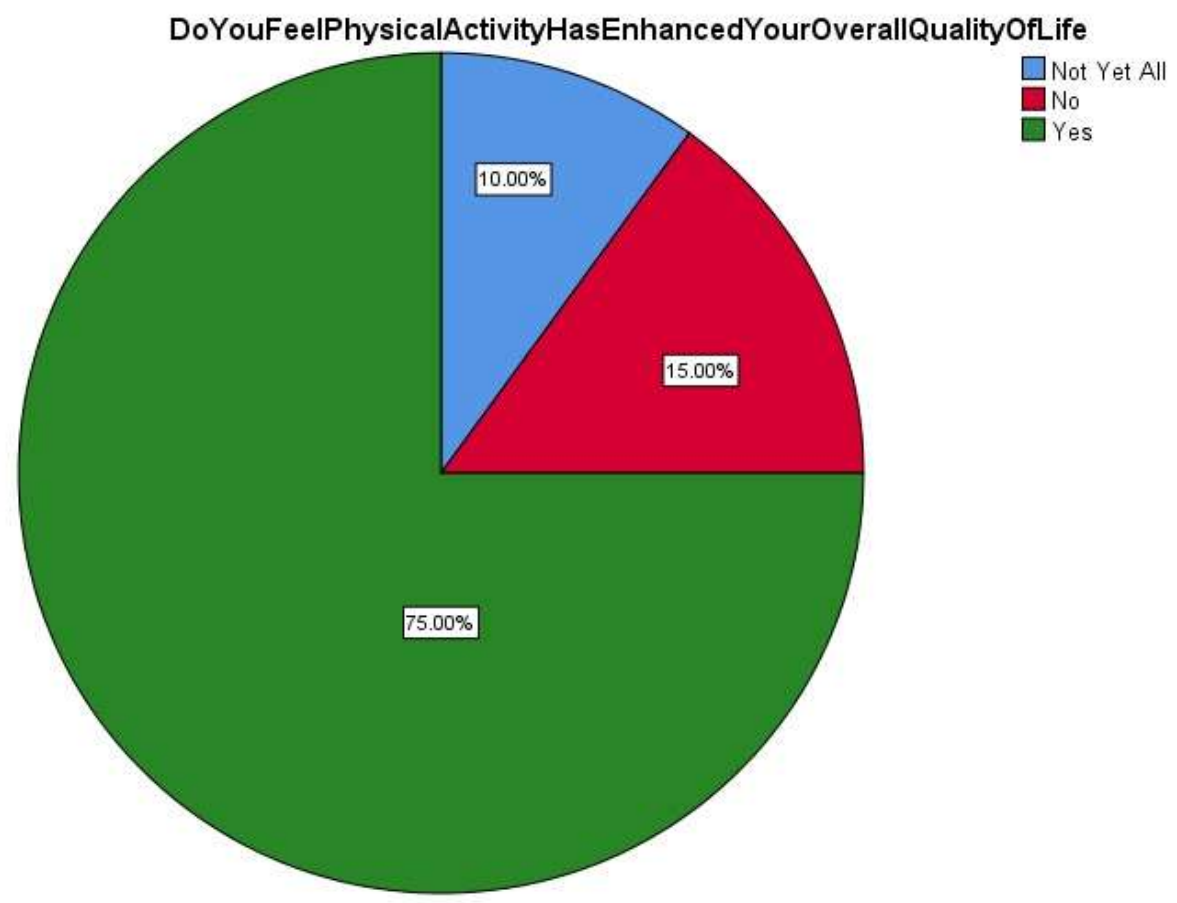

Fig 5: Shows the response of the participants who felt physically enhanced their life during lockdown days. It shows $\mathbf{7 5 \%}$ says Yes, $15 \%$ said No, $10 \%$ said not yet all. Green indicates yes, red indicates no, blue indicates not yet all

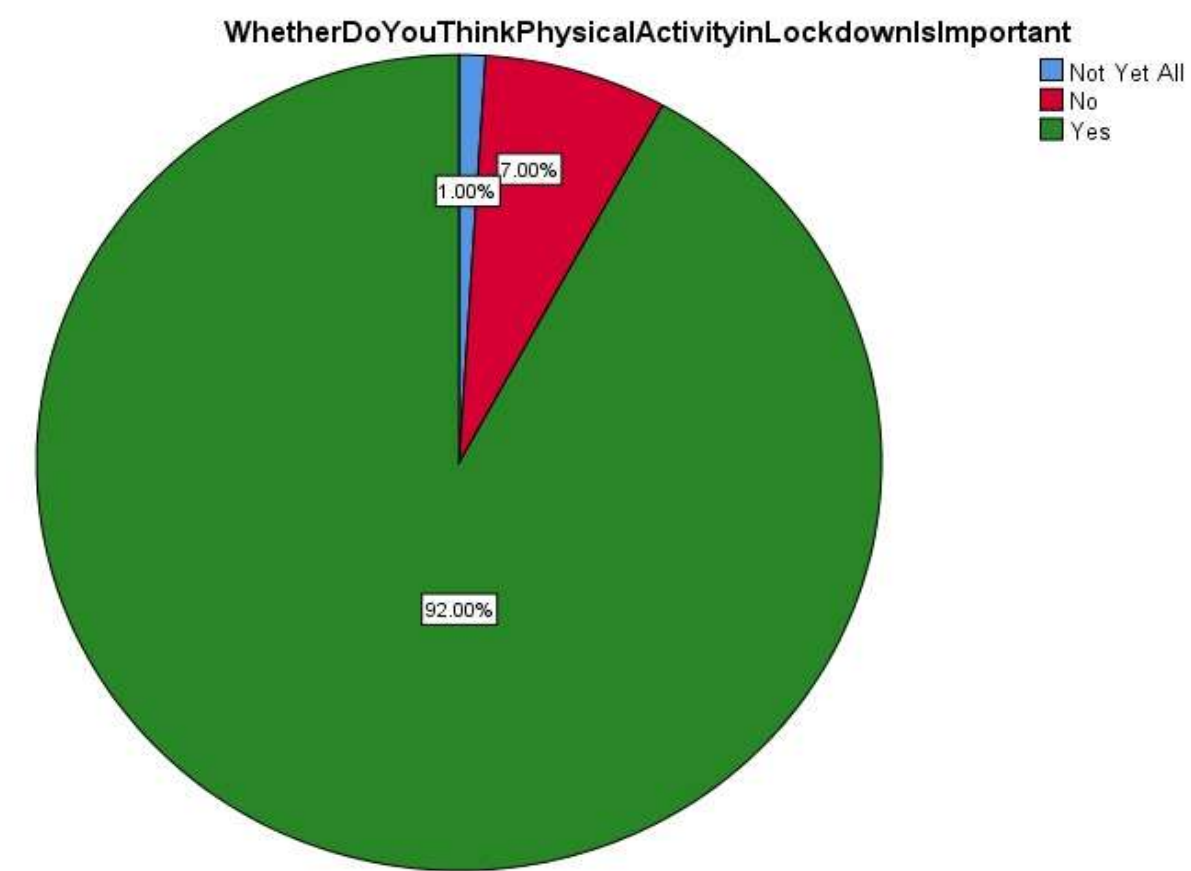

Fig 6: Shows the distribution of the participants who felt physical activity is important during lockdown days. It shows $92 \%$ says Yes, $7 \%$ said No, $1 \%$ said not at all. Green indicates yes, red indicates no and blue indicates not yet all 


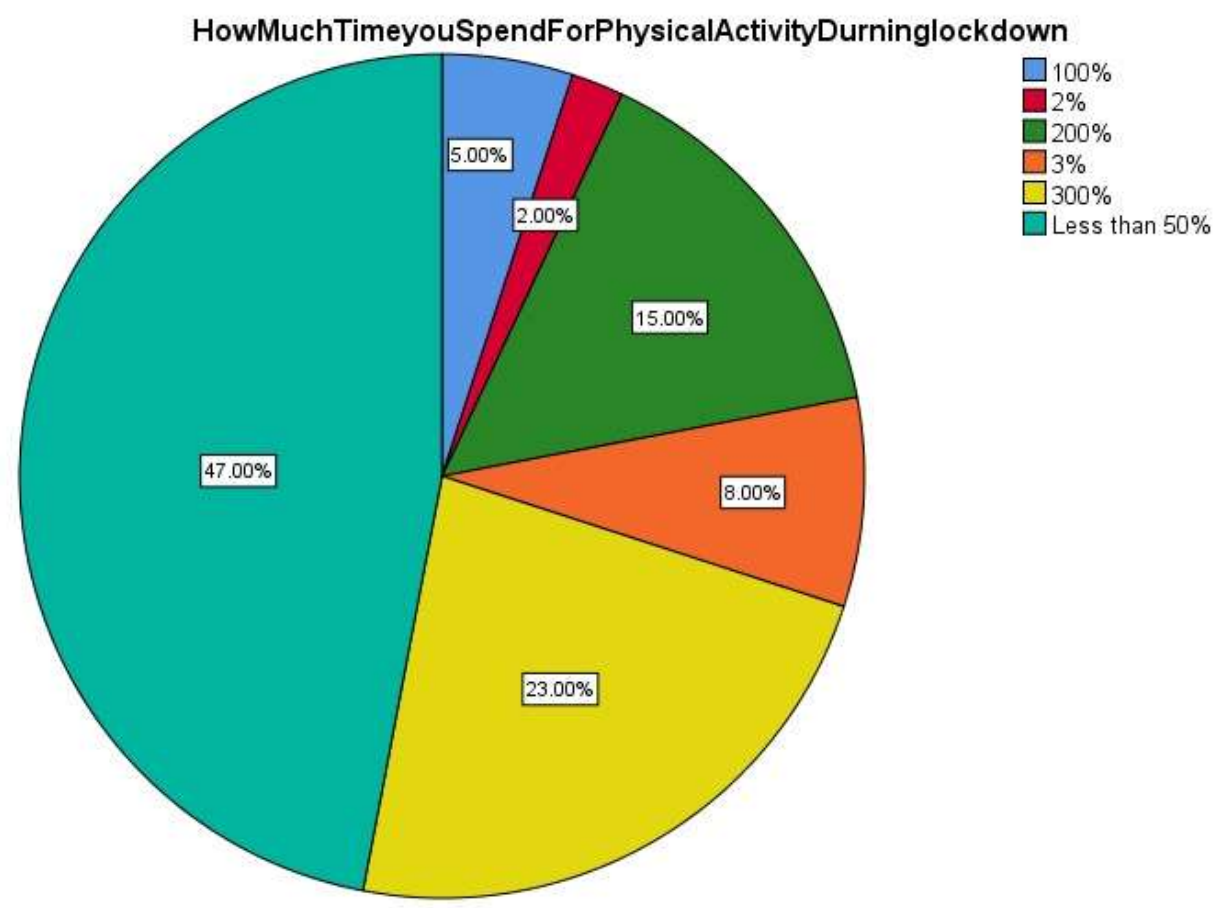

Fig 7: Shows the distribution of the time spent by the participants, physical activity during lockdown. It shows the time spent by the students for physical activity during lockdown, $5 \%$ students spend $100 \%, 17 \%$ students spend $\mathbf{7 5 \%}, \mathbf{5 0} \%$ students spend $35 \%$, less than $50 \%$ students $47 \%$ for their fitness level.

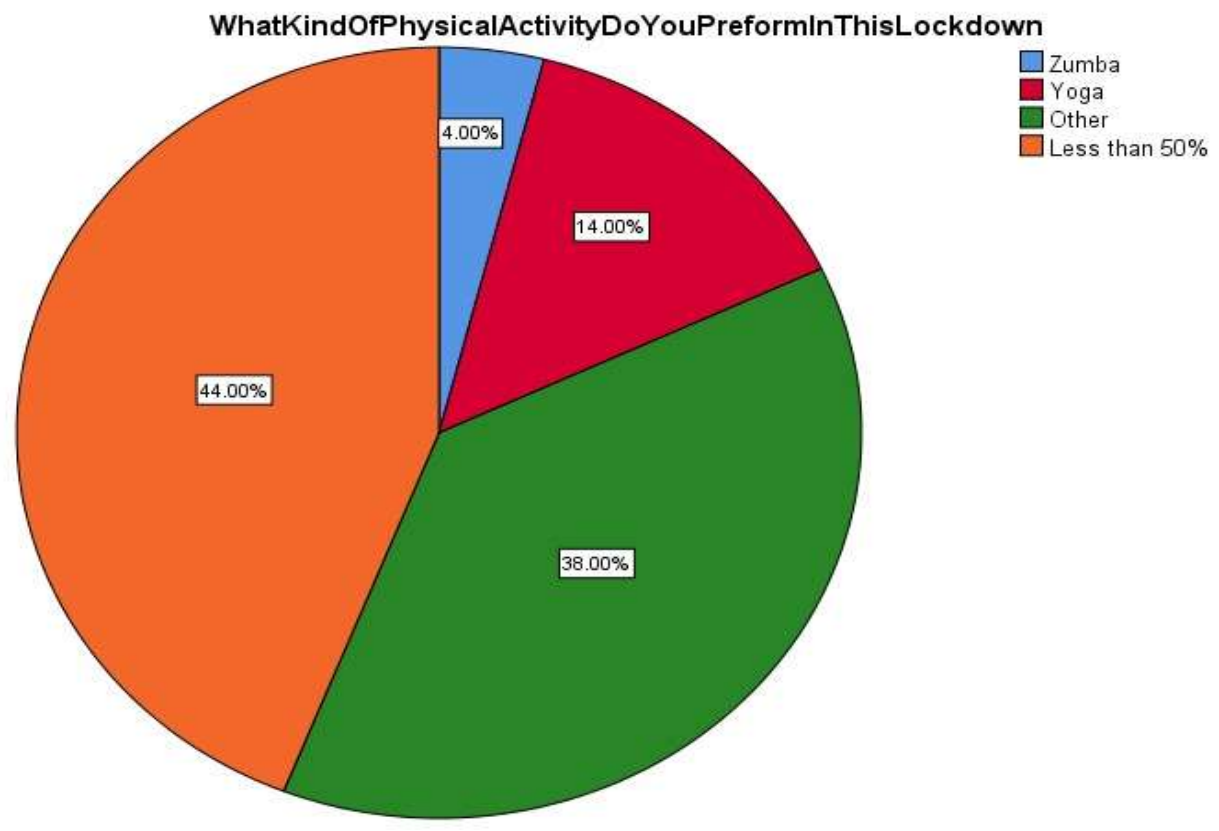

Fig 8: Shows the distribution of the participants what kind of physical activity is done during lockdown days. It shows $4 \%$ of the students did zumba, $14 \%$ of the students did yoga, $38 \%$ did other types of activities. Blue indicates zumba, red indicates yoga, green indicates others. 


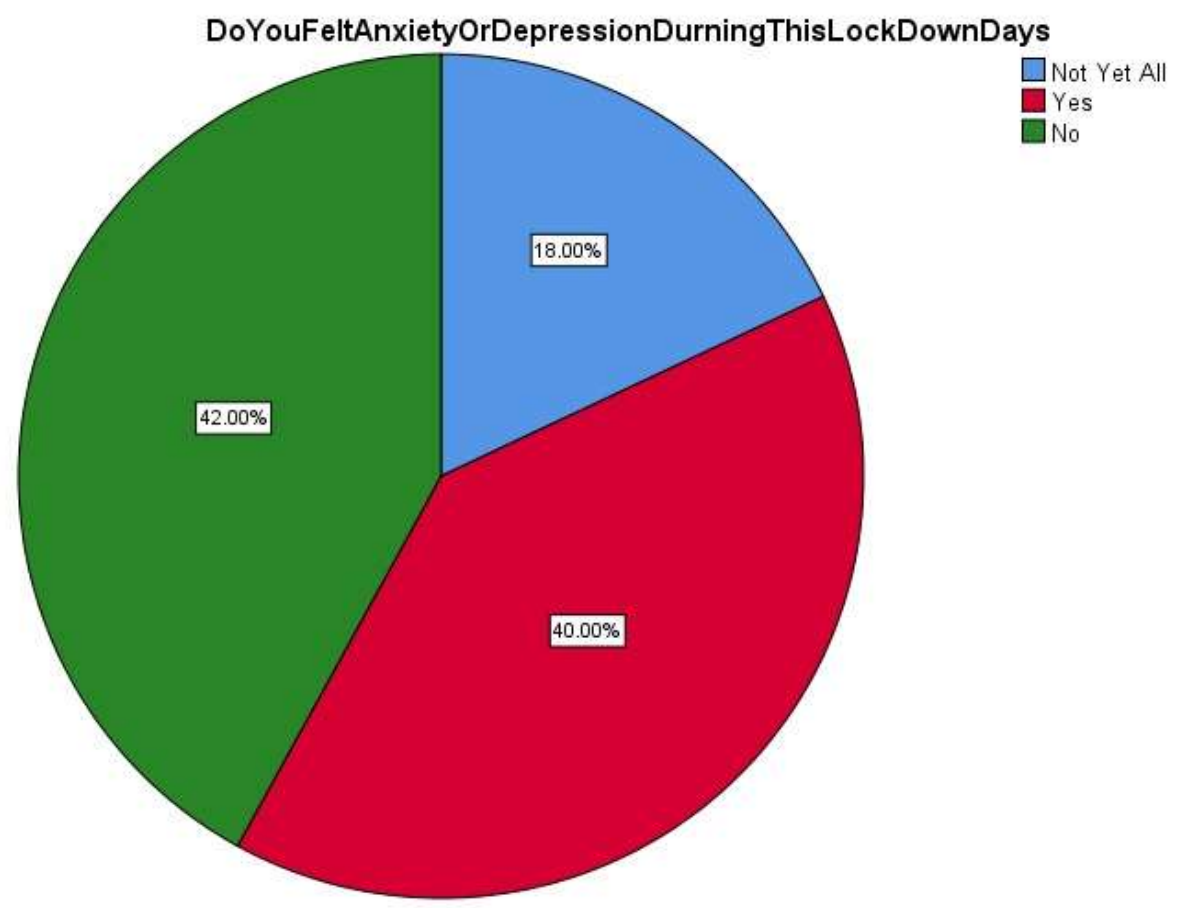

Fig 9: Shows the distribution of anxiety and depression by the participants during lockdown days. It shows $40 \%$ of the participants felt anxiety and depression, $41 \%$ of the participants did not feel, $19 \%$ of the participants felt anxiety and depression during the lockdown days. red indicated yes, green indicates no, blue indicates not yet all

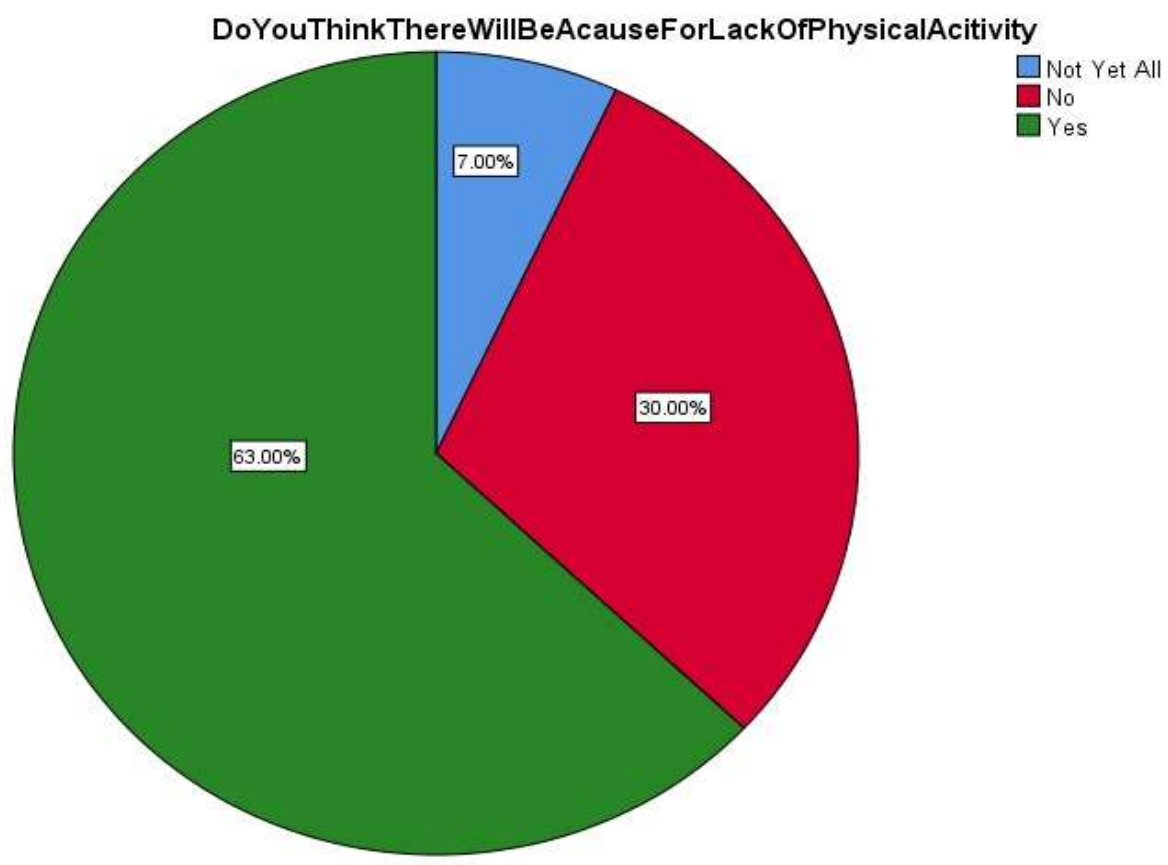

Fig 10: Shows the distribution of the participants whether they think there will be cause for physical activity is done during lockdown days. It shows $63 \%$ of students says yes, $30 \%$ of the student said no, $7 \%$ of the student said not yet all.green indicates yes, red indicates no, blue indicates not yet all. 


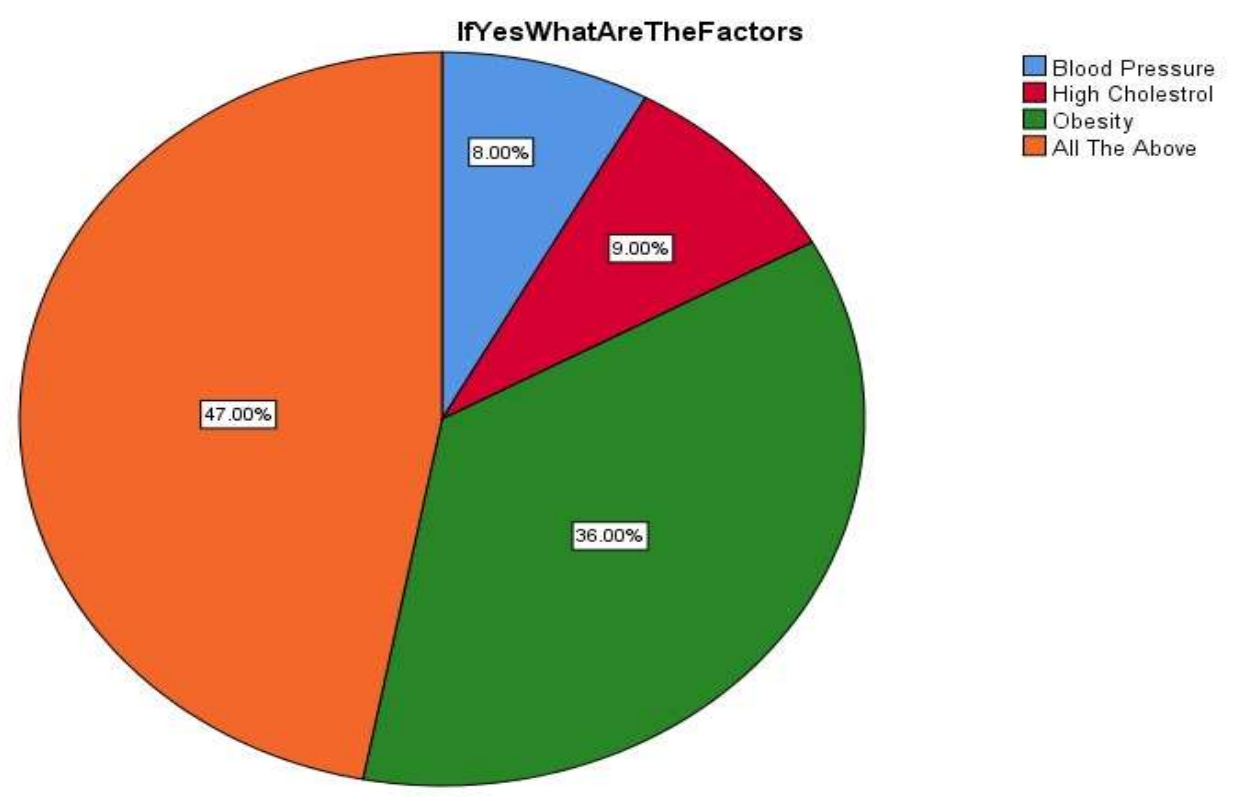

Fig 11: Shows the distribution of the participants' knowledge about the factors affecting lack of physical activity. It shows $8 \%$ student says Blood pressure, $9 \%$ of the student said High cholesterol, $36 \%$ of the student says obesity and $47 \%$ of the students says all the above. Blue indicates blood pressure, red indicates high cholesterol, green indicates obesity, orange indicated all the above.

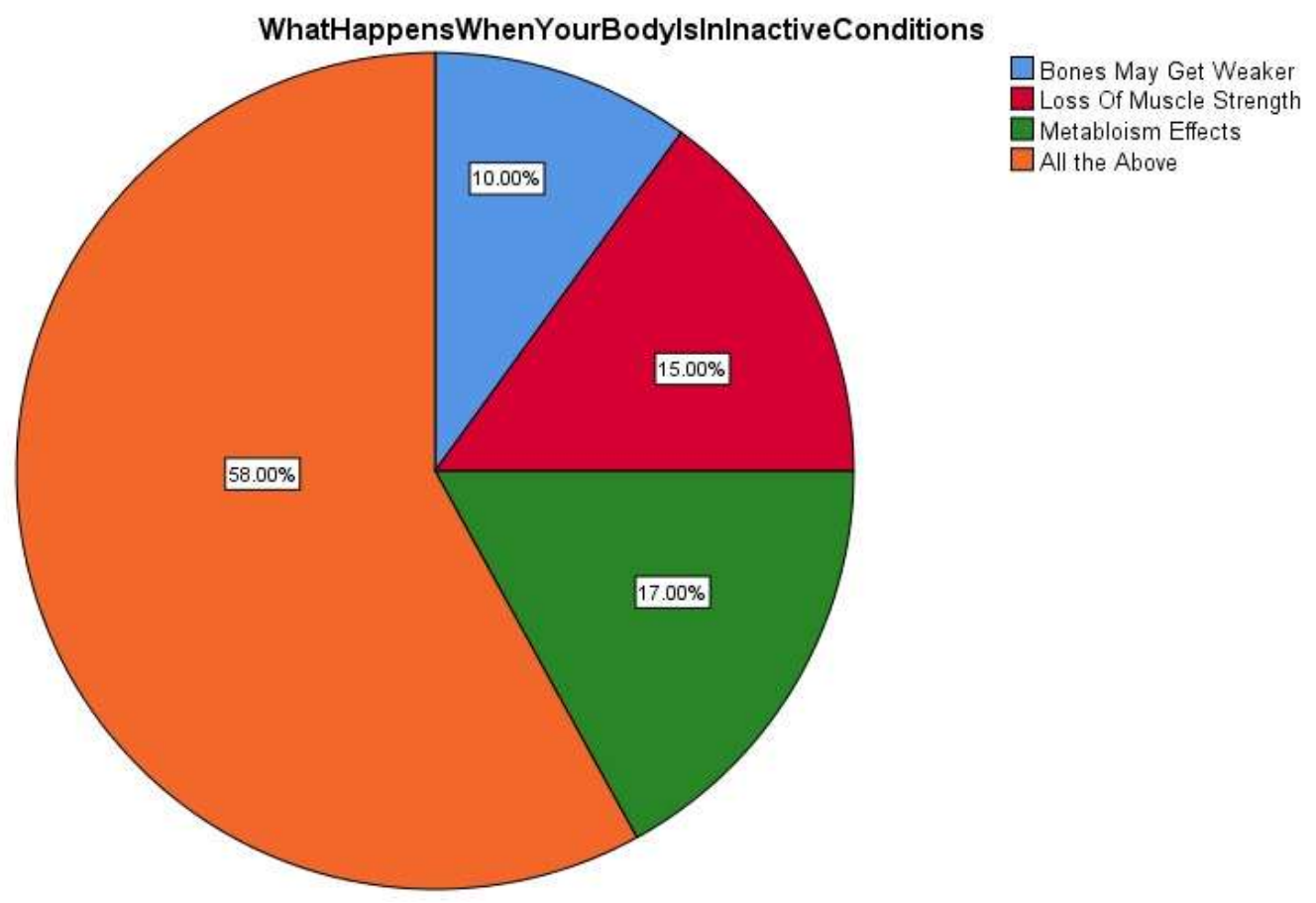

Fig 12: Shows the various outcomes of physical inactivity. It shows $10 \%$ participants say Bones may get weaker, $15 \%$ participants say loss of muscle strength, $17 \%$ say metabolism may get affected, $58 \%$ participants say all the above.blue indicates bones may get weaker, red indicates loss of muscle strength, green indicates metabolism effects, orange indicates all the above 


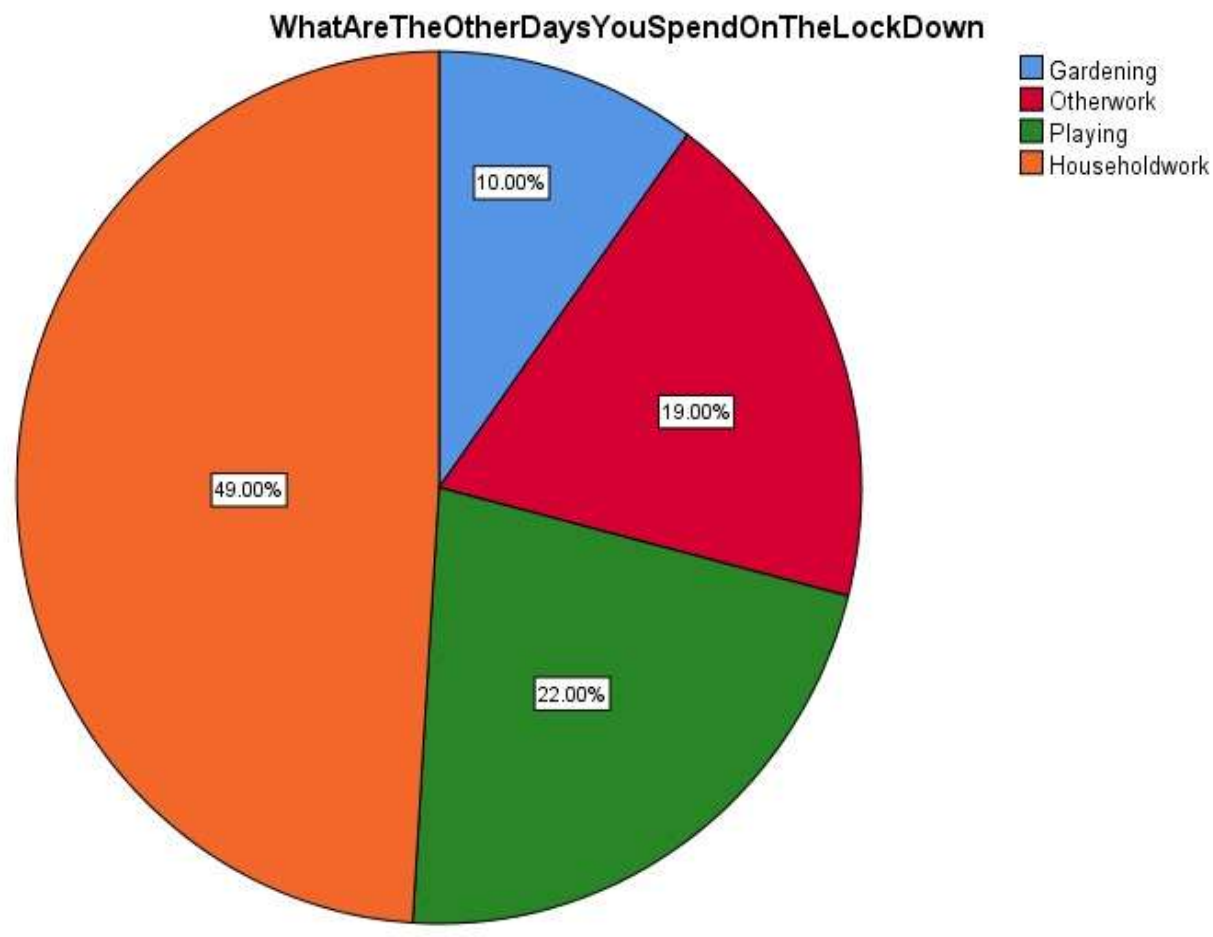

Fig 13: Shows the distribution of the participants' ways of spending time during the lockdown days. It shows $10 \%$ student says gardening, $19 \%$ of the student said other work, $22 \%$ of the student says playing and $49 \%$ of the students says doing household work blue indicated gardening, red indicates other work, green indicates playing, orange indicates household work

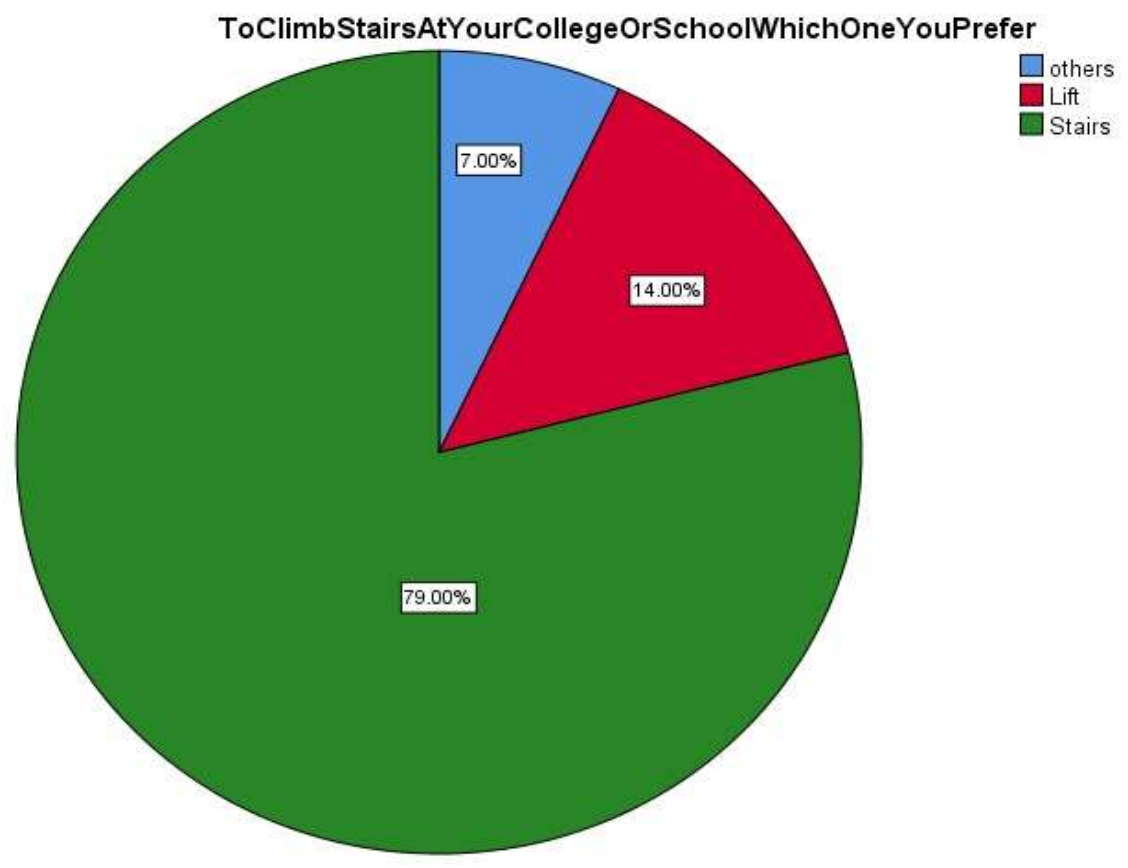

Fig 14: Shows the percentage of the participants preference to use lift, stairs or other ways to climb. It shows $79 \%$ student says stairs, $14 \%$ of the student said Lift, $7 \%$ of the students said others green indicates stairs, red indicates lift, blue indicates others 


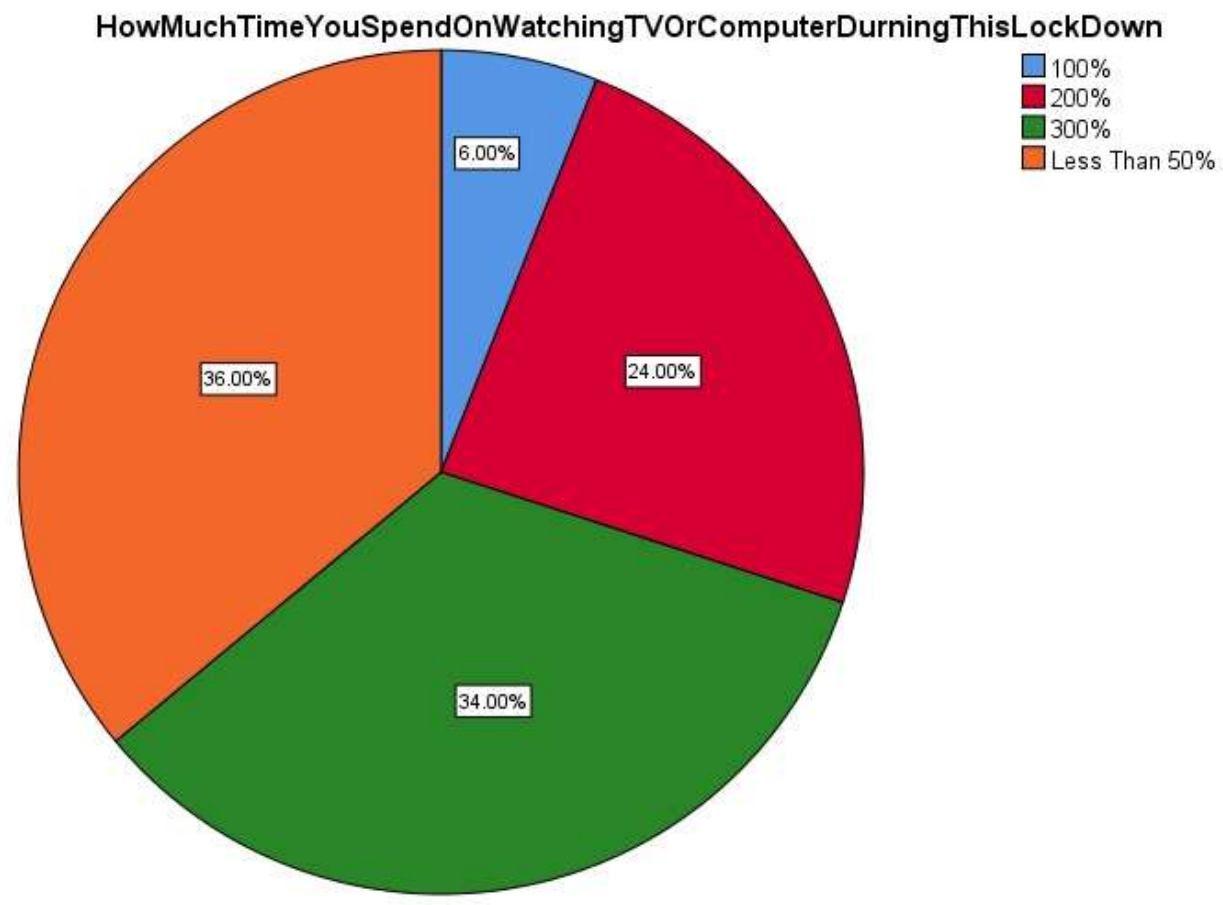

Fig 15: Show the distribution of the participants' time spent on watching TV or Computer during lockdown days. It shows $6 \%$ students spend $100 \%$ of his time on watching tv or computer, $24 \%$ spend $200 \%$ of its time and $34 \%$ spend $300 \%$ of its time and $38 \%$ spend less than $50 \%$, Blue $100 \%$, red $200 \%$, green $300 \%$, orange less than $50 \%$

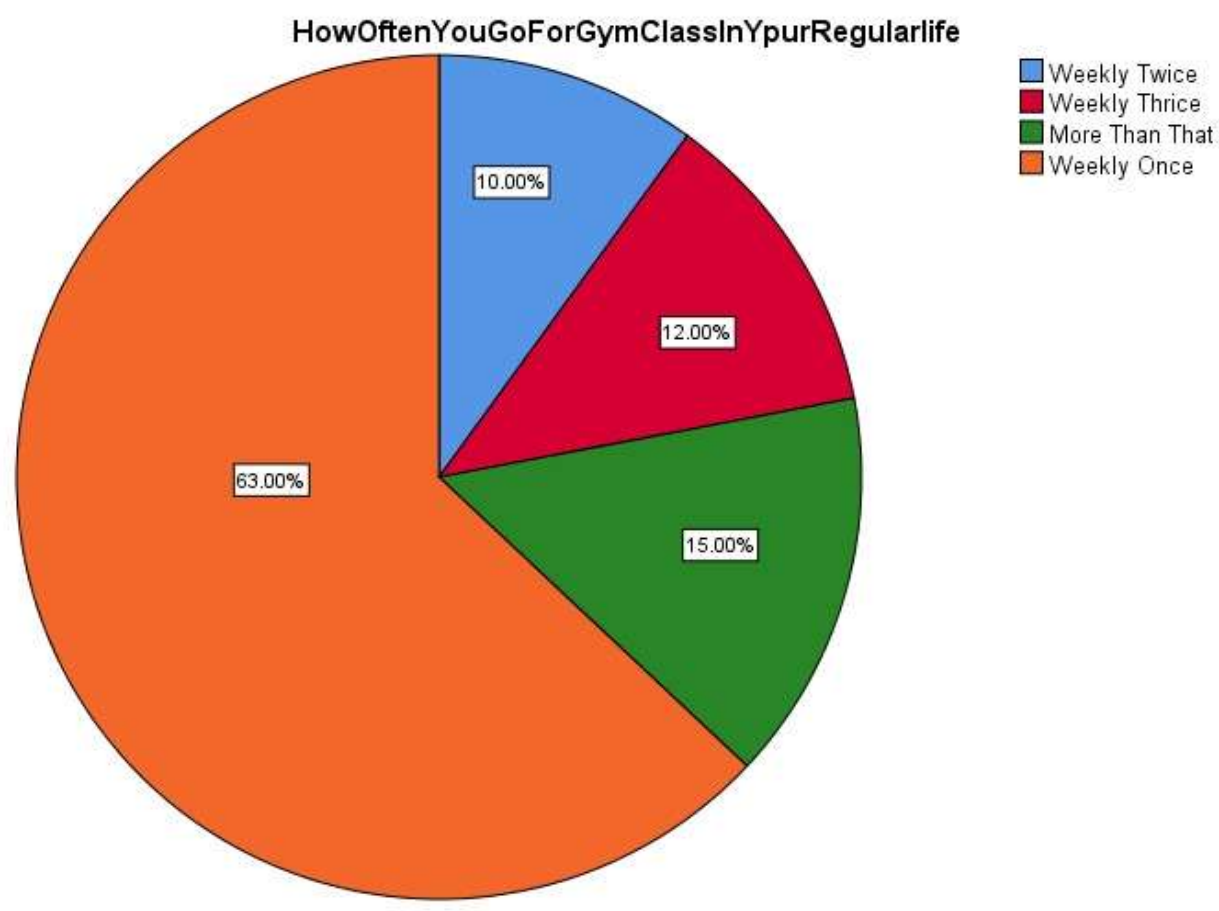

Fig 16: Shows the distribution of the participants' response on the frequency of gym visits. It shows $10 \%$ student says weekly twice, $12 \%$ of the student said weekly thrice, $15 \%$ of the student says more than that and $63 \%$ of the students said weekly once.blue indicates weekly twice, red indicates weekly thrice, green indicates more than that, orange indicates weekly once 


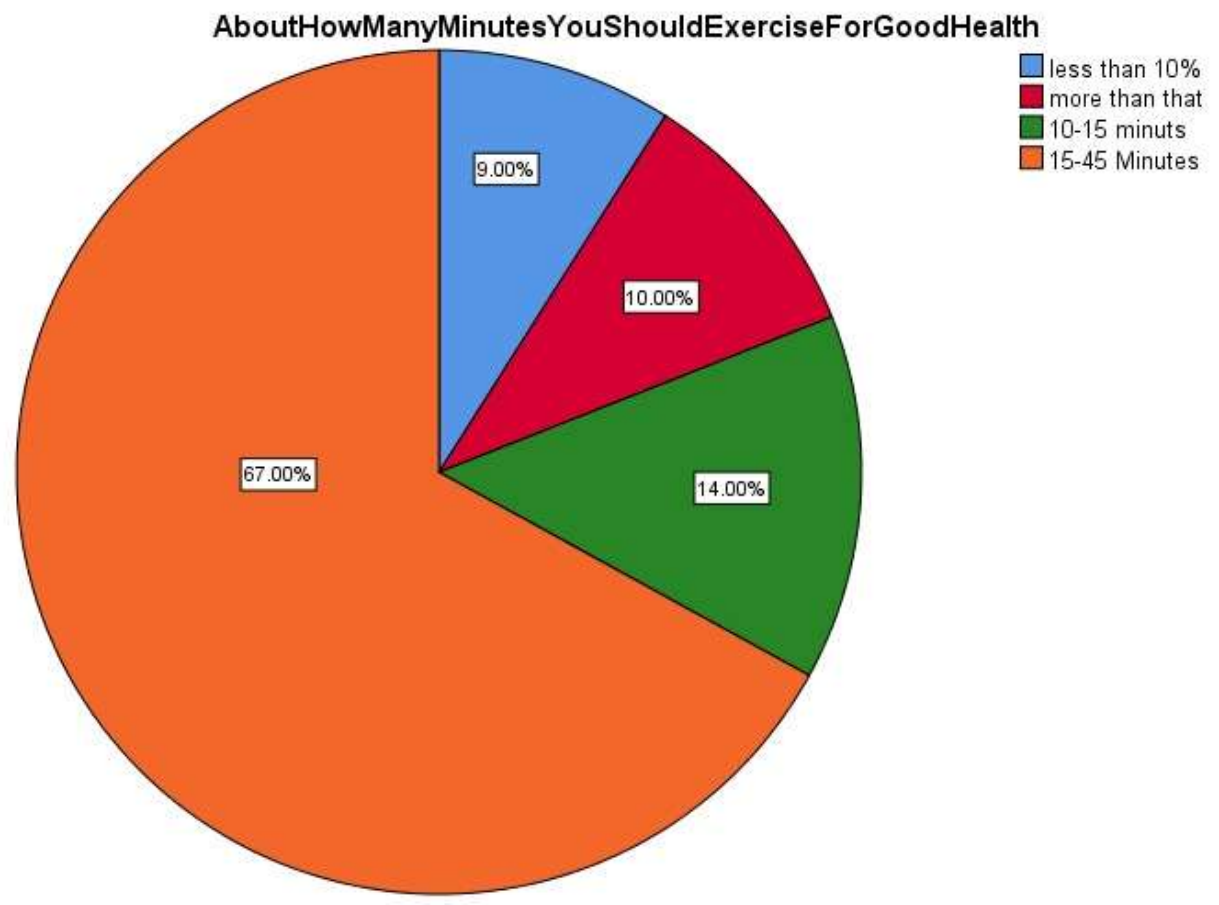

Fig 17: Shows the distribution of the participants' response about time spent for exercise for good health. It shows $9 \%$ participants spend less than $10 \%, 10 \%$ of the participants spend more than a hour, $13 \%$ of the participants spend 10-15 minutes, $67 \%$ of the participants spend 15-45 minutes, blue indicates less than $10 \%$, red indicates more than that, green indicated 10-15minutes and orange indicates 15-45 minutes

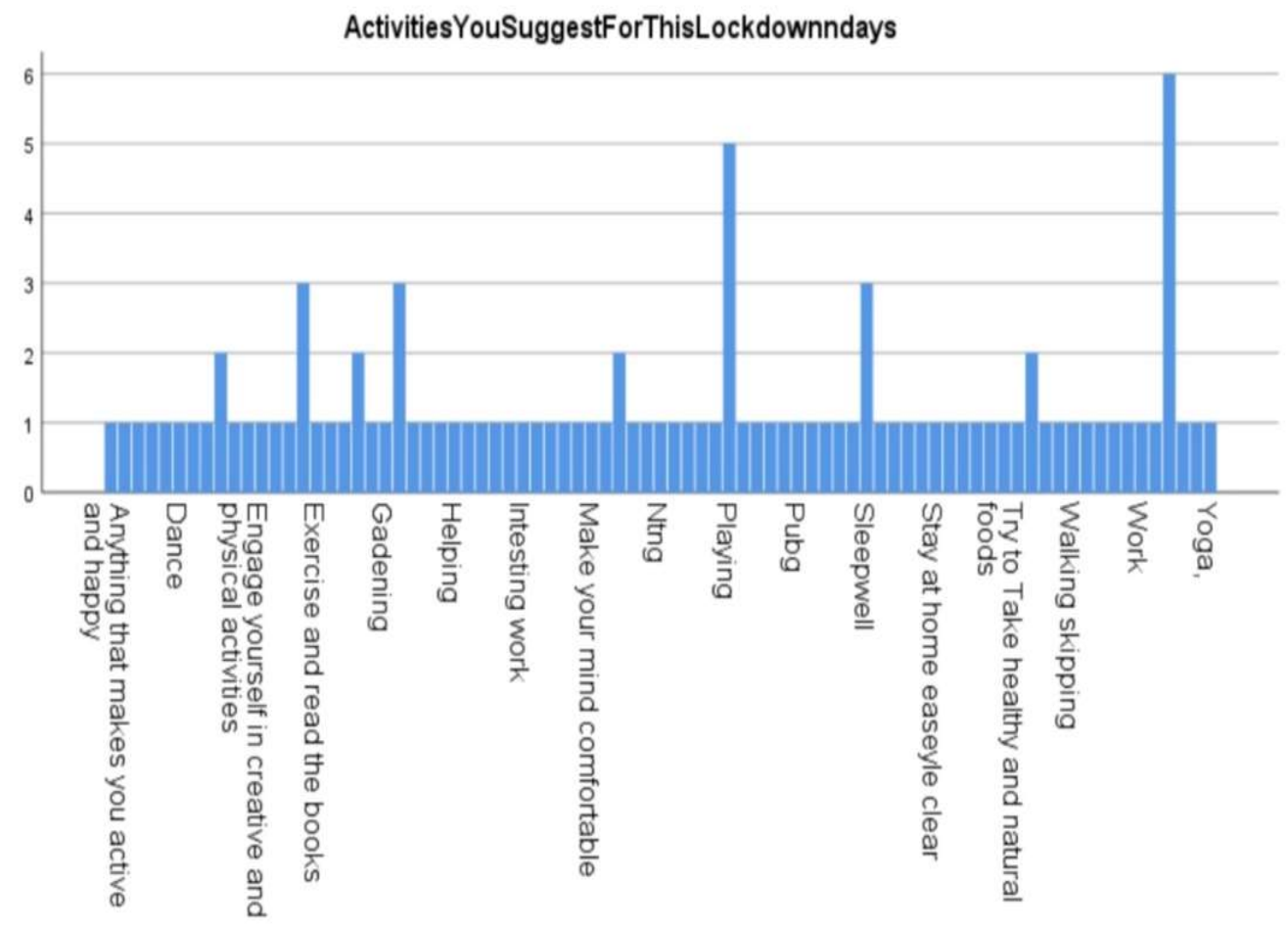

Fig 18: Shows the distribution of the activities suggested by the participants during lockdown days. Most of the participants say Exercise, Yoga, cooking etc 


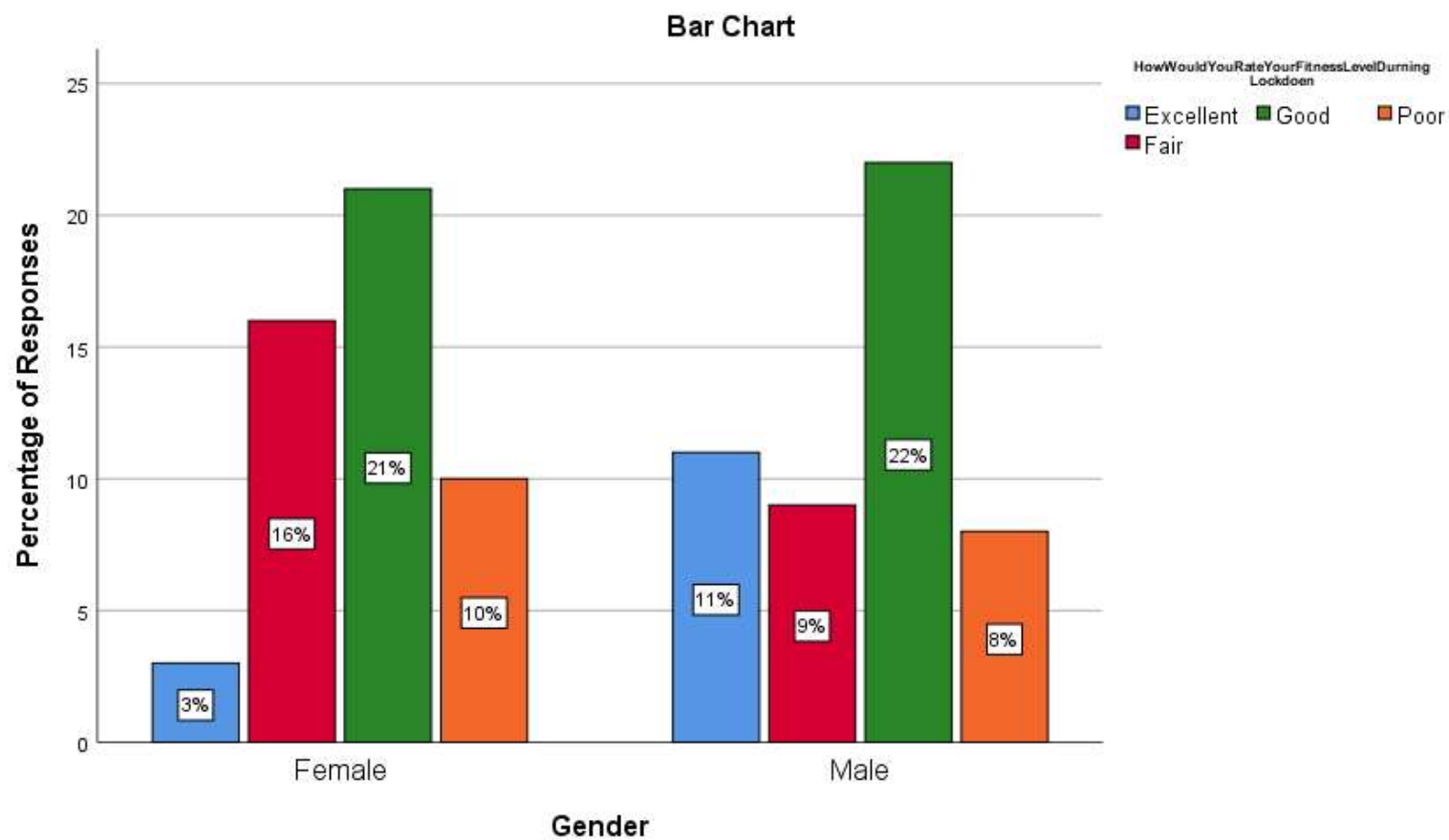

Fig 19: The bar graph represents the association between the gender and fitness rate of the respondents . $X$ axis represents the gender and $\mathrm{Y}$ axis represents the number of responses for the amount of overall activity.Blue denotes excellence, green denotes good, orange denoted good, red denotes fair. Both males and females responded their overall rate fitness activity was good during lockdown .Pearson chi square test shows $p$ value is $0.290,(p$ value $>$ 0.05) Hence, it is statistically not significant.

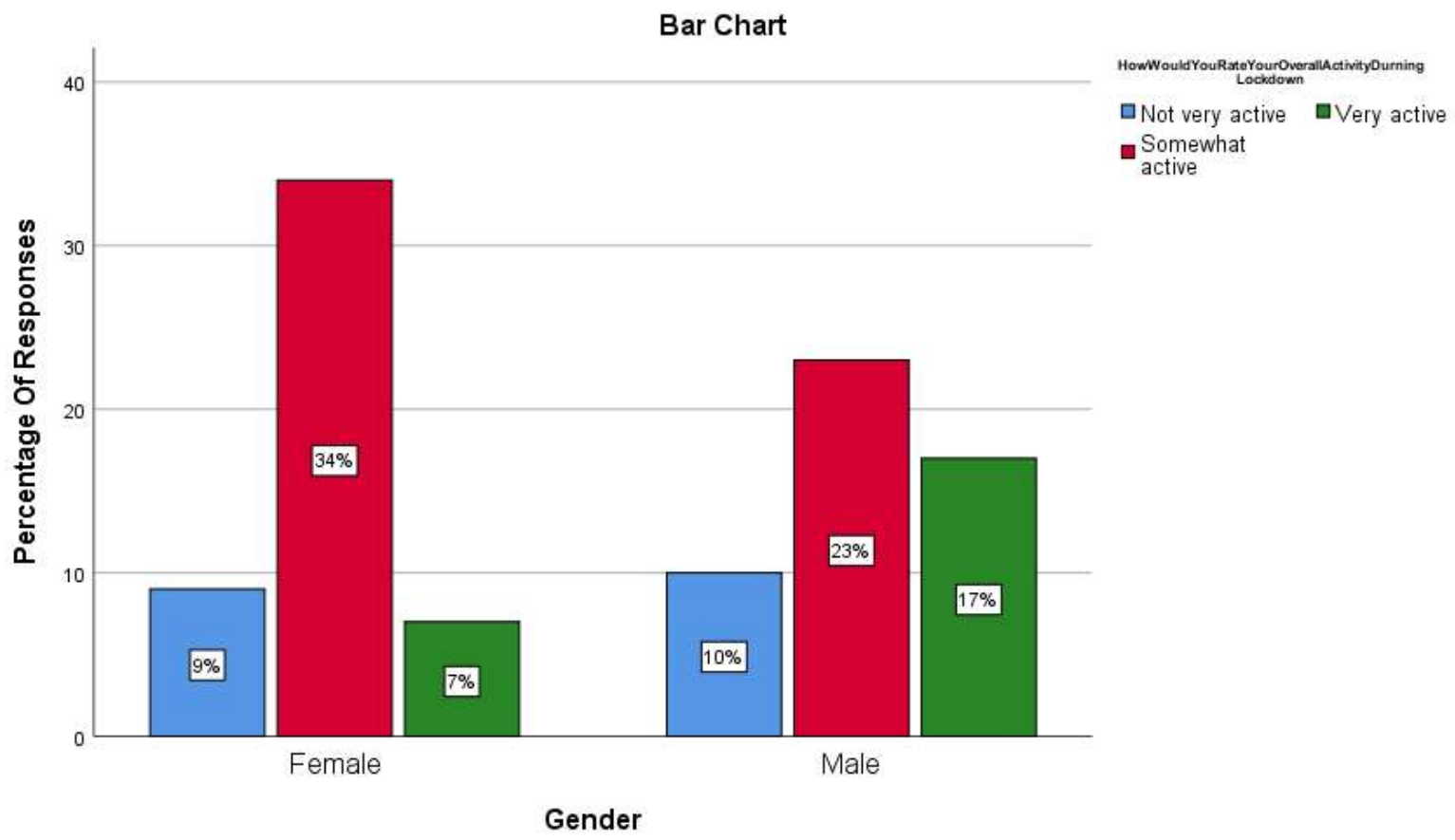

Fig 20: The bar graph represents the association between the gender and the overall activity of the respondents during lockdown..$X$ axis represents the gender. $Y$ axis represents the number of responses for the amount of overall activity .Blue denotes not very active, green denotes very active, red denotes somewhat active. Females show a better overall rate of activity during lockdown than males. .Pearson chi square test shows $p$ value is $0.097,(p$ value $>0.05)$ Hence, it is statistically not significant 


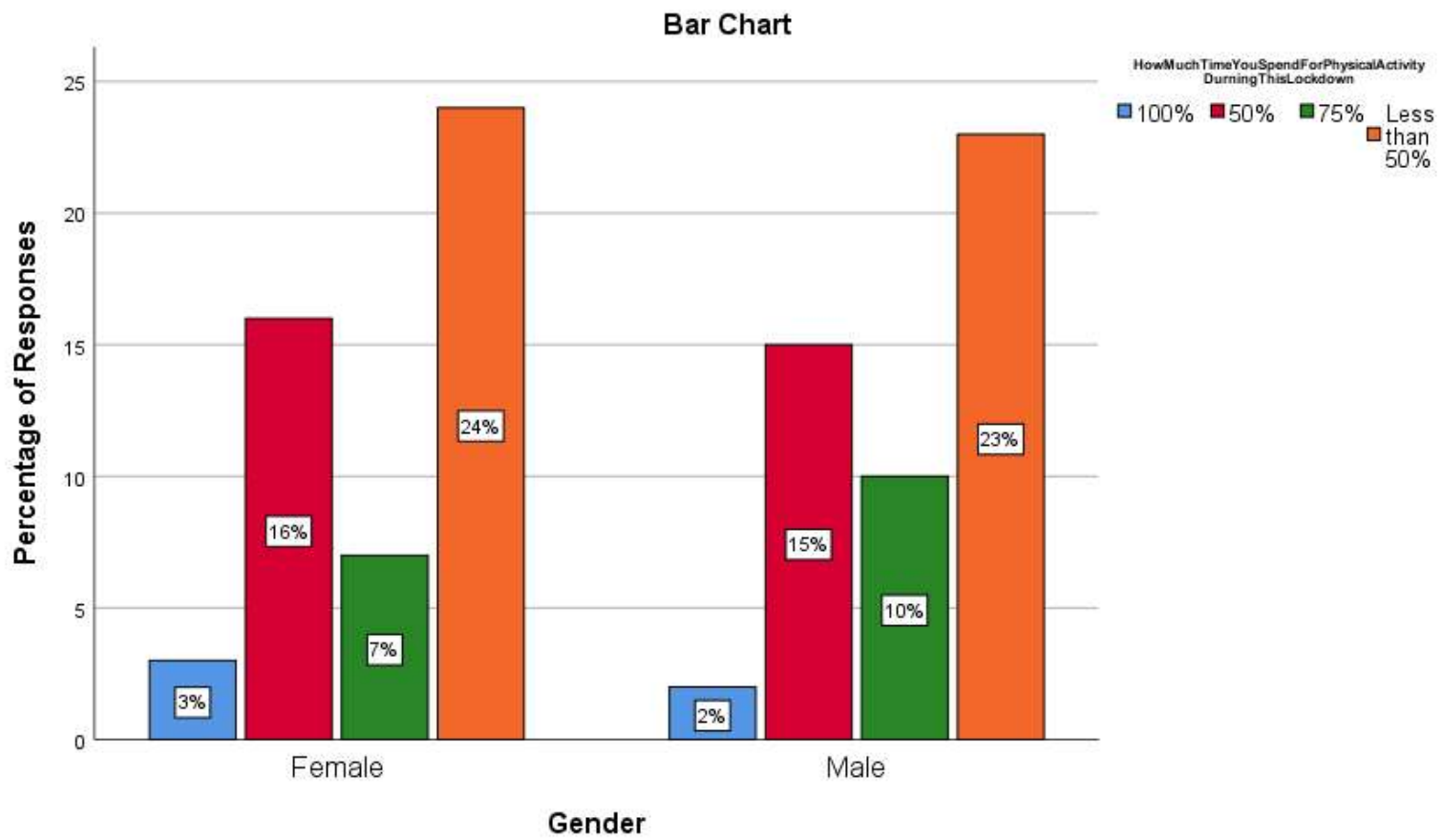

Fig 21: The bar graph represents the association between the gender and the time spent for physical activity by the respondents . $\mathrm{X}$ axis represents the gender and $\mathrm{Y}$ axis represents the number of responses for the amount of overall activity. Blue denotes $100 \%$ spent time for physical activity, red denotes $50 \%$, green denotes $75 \%$ ang orange represents less than $50 \%$. Some females spent more time on physical activity than males. Pearson chi square test shows $p$ value is 0.112 , ( $p$ value $>0.05$ ) Hence, it is statistically not significant

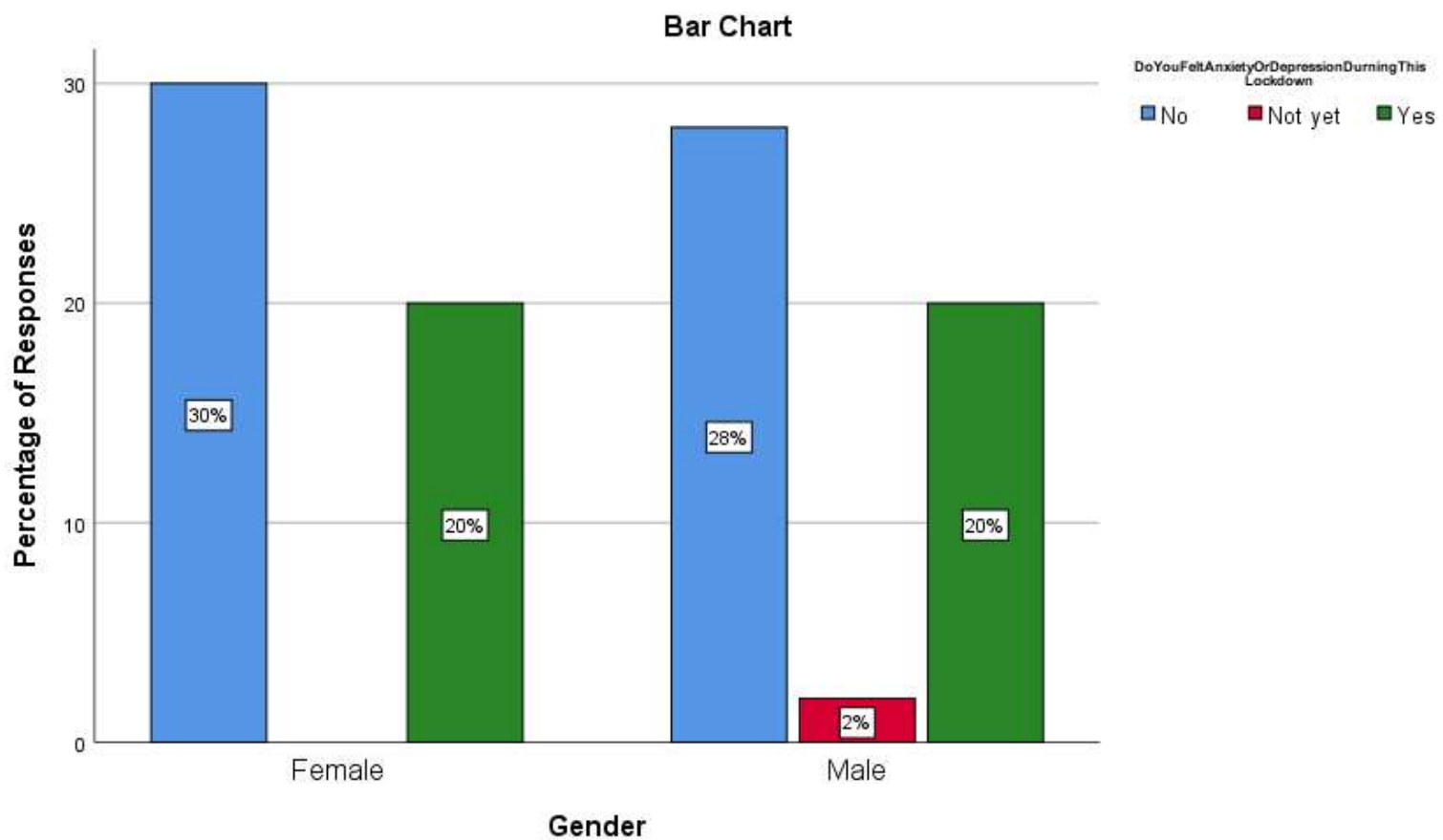

Fig 22: The bar graph represents association between the gender and experience of depression or anxiety by the respondents.$X$ axis represents the gender $Y$ axis represents the number of responses for the amount of the overall activity. Green denotes yes, blue denotes no and red denotes not yet all. Both males and females were slightly anxious and experienced depression during lockdown.Pearson chi square test shows $p$ value is 0.099 , ( $p$ value $>0.05)$ Hence, it is statistically not significant 


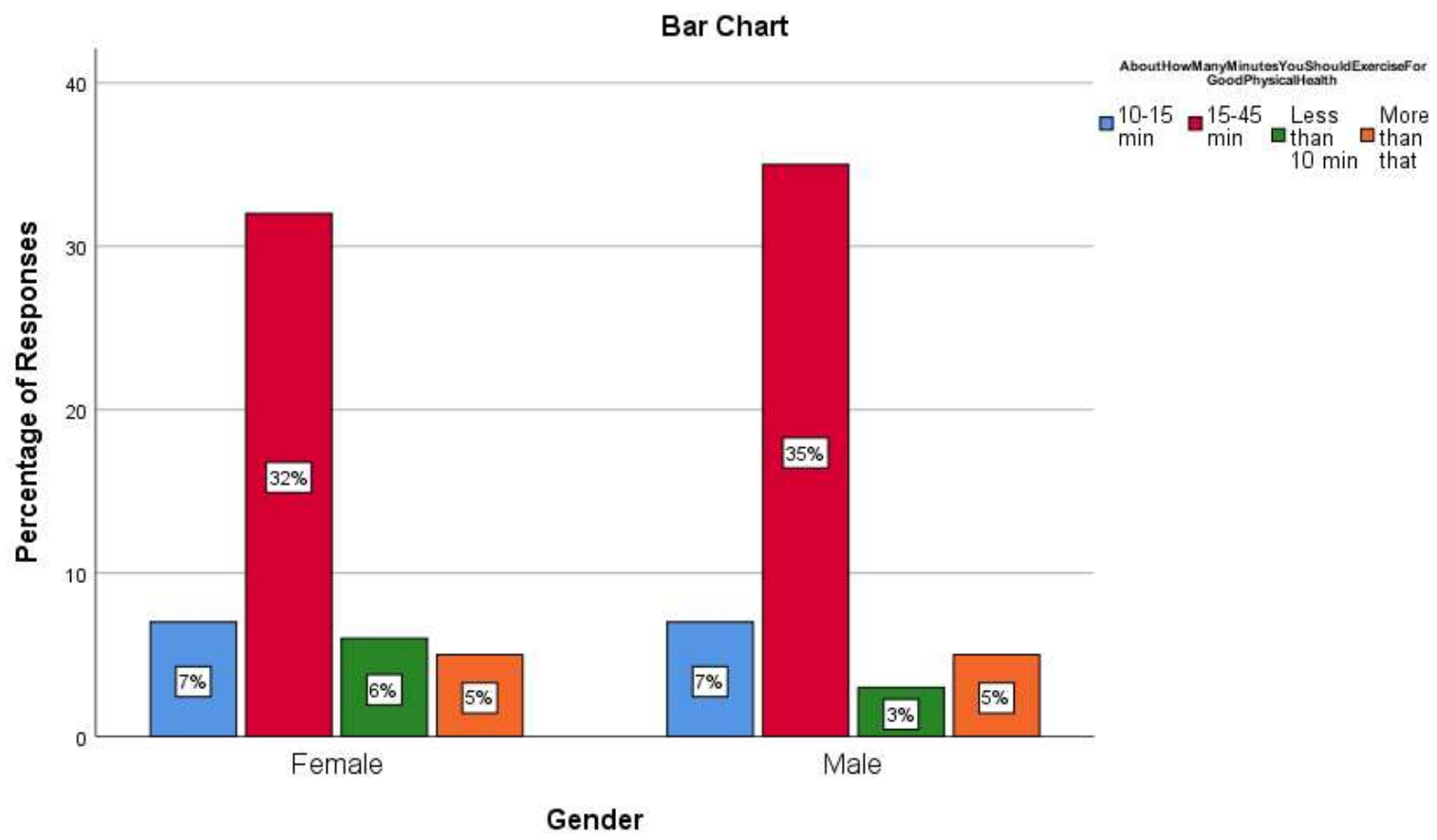

Fig 23: The bar graph represents association between the gender and response regarding time spent for exercise for good health by the respondents.$X$ axis represents the gender and $Y$ axis represents the number of responses for the amount of overall activity the overall activity. Blue denotes 10-15 minutes to get good physical health, red denotes 1545 minutes, green denotes less than 10 minutes and orange indicates more than that. Overall activity between males and females is almost the same. Some females spent less time for physical activity than males. Pearson chi square test shows $p$ value is 0.100 , ( $p$ value $>0.05$ ) Hence, it is statistically not significant

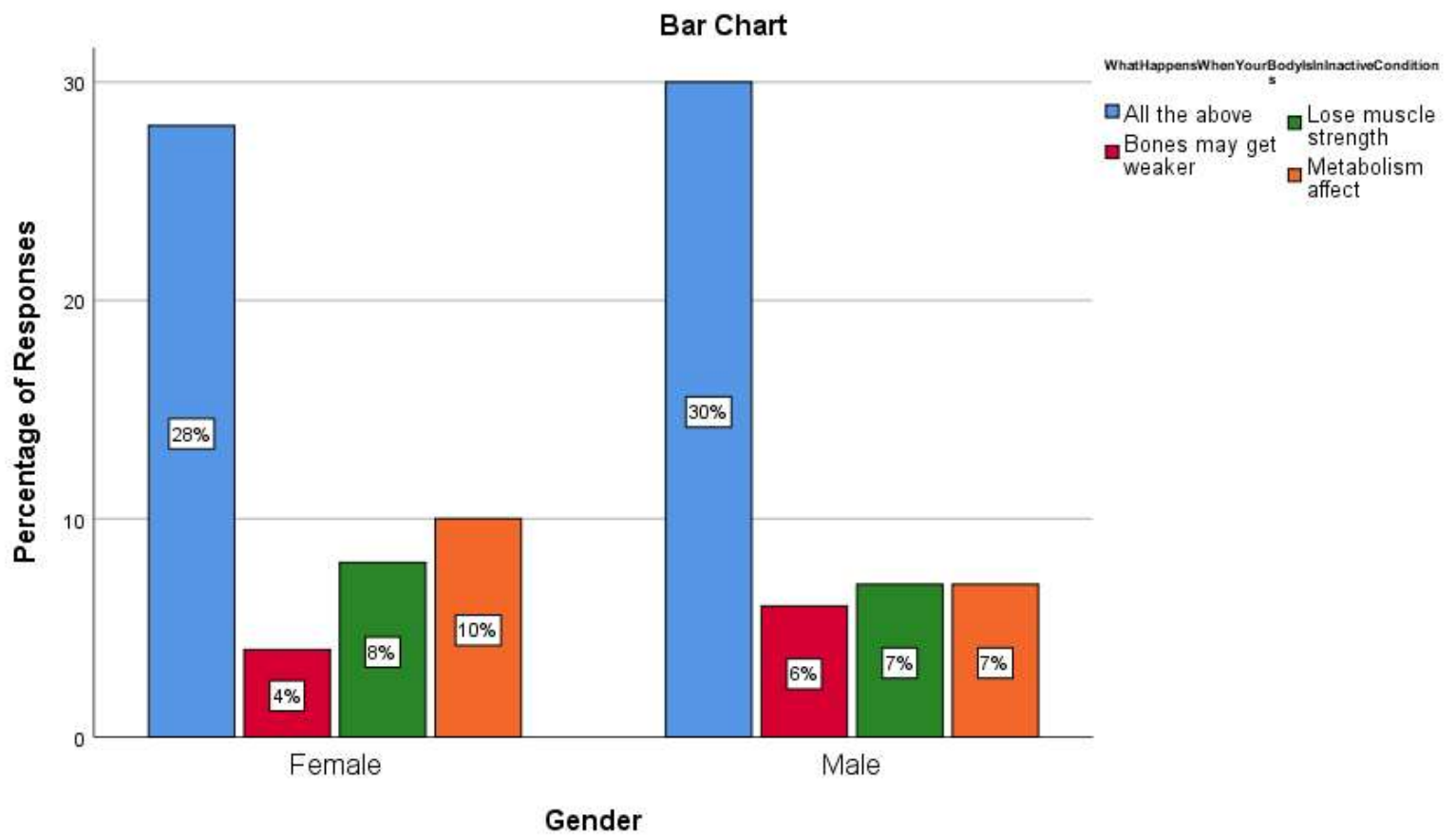

Fig 24: The bar graph shows the association between the gender and response for the outcome of inactivity. $X$ axis represents the gender and $\mathrm{Y}$ axis represents the number of respondents.. Red denotes bones may get weaker, Green denotes loss of muscle strength, orange denotes metabolism effect and blue indicates all the above. Overall reasons for inactivity between males and females is almost the same. Pearson chi square test shows $p$ value is $0.100,(p$ value $>$

0.05) Hence, it is statistically not significant 


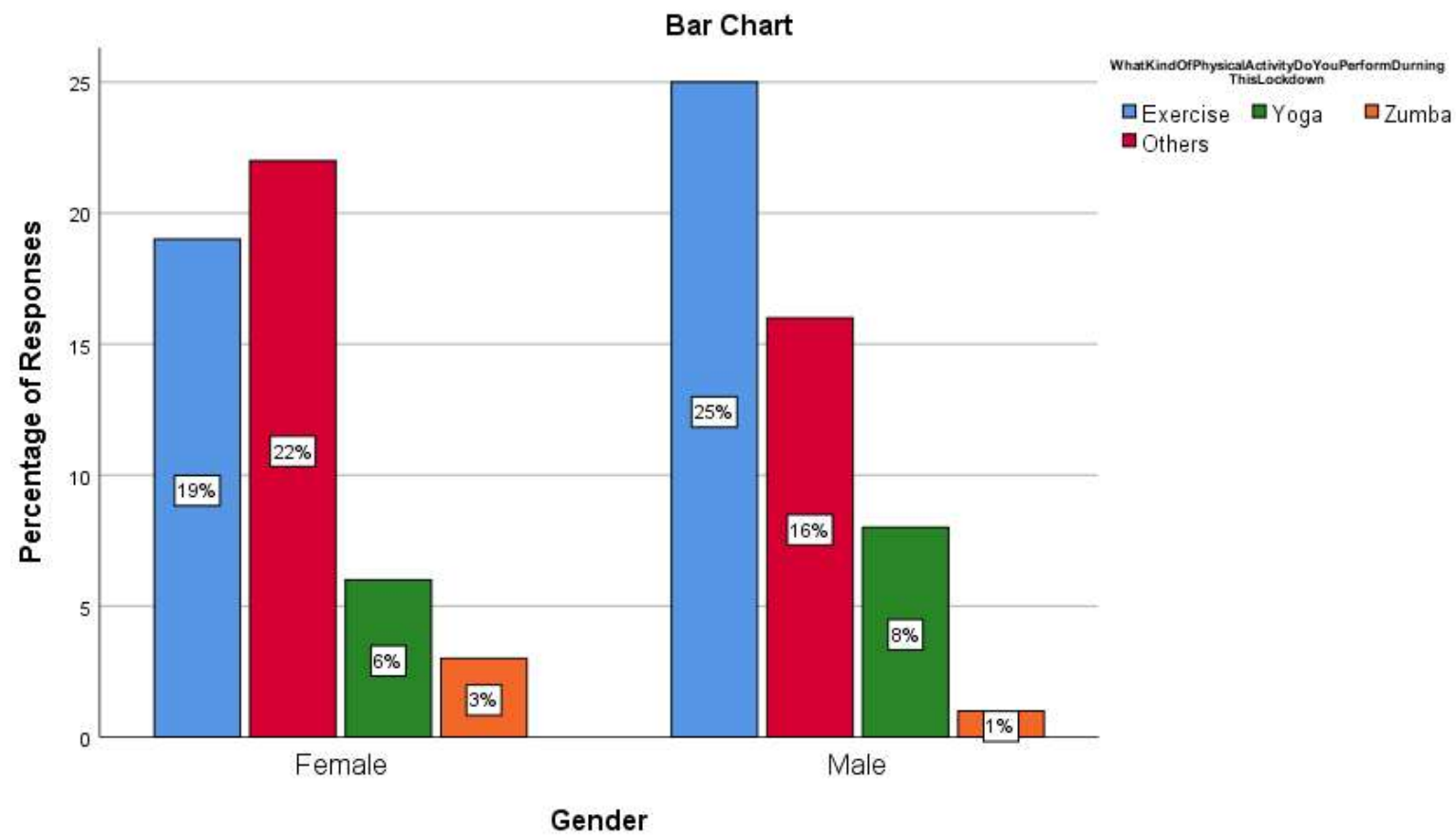

Fig 25: The bar graph represents the association between the gender and type of activity performed during lockdown by the respondents. $\mathrm{X}$ axis represents gender and $\mathrm{Y}$ axis represents the number of responses for the type of overall activity. Blue denotes exercise, Green denotes yoga, orange denotes zumba, red denotes others. Overall activity between males and females is almost the same. More males opted for physical exercise whereas females preferred zumba. Pearson chi square test shows $p$ value is $0.097,(p$ value $>0.05)$ Hence, it is statistically not significant

\section{CONCLUSION}

This study revealed the knowledge and awareness of the importance of physical activity is considerable and the measures to improve the same are welcomed by the participants. According to the association analysis, both males and females showed an equal amount of physical inactivity which has to be improved for the betterment of the society and country in order to avoid obesity and obesity related systemic disorders. Students must know the advantages of physical activity and spend time for it to lead a healthy life.

\section{REFERENCE}

[1] Lipošek S, Planinšec J, Leskošek B, Pajtler A. Physical Activity Of
University Students And Its

Relation To Physical Fitness And Academic Success. Annales Kinesiologiae. 2018;9(2):89-104.

[2] Alkhateeb SA, Alkhameesi NF, Lamfon GN, Khawandanh SZ, Kurdi LK, Faran MY, et al. Pattern of physical exercise practice among university students in the Kingdom of Saudi Arabia (before beginning and during college): a crosssectional study. BMC Public Health. 2019 Dec 21;19(1):1716.

[3] Phan D-V, Chan C-L, Pan R-H, Yang N-P, Hsu H-C, Ting H-W, et al. A Study of the Effects of Daily Physical Activity on Memory and 
Attention Capacities in College

Students. J Healthc Eng. 2018 Mar 22;2018:2942930.

[4] Allender S, Cowburn G, Foster C. Understanding participation in sport and physical activity among children and adults: a review of qualitative studies. Health Educ Res. 2006 Dec;21(6):826-35.

[5] Powell LM, Chaloupka FJ, Slater SJ, Johnston LD, O’Malley PM. The Availability of Local-Area Commercial Physical ActivityRelated Facilities and Physical Activity Among Adolescents. Am J Prev Med. 2007 Oct 1;33(4, Supplement):S292-300.

[6] Lowry R, Galuska DA, Fulton JE, Wechsler H, Kann L, Collins JL. Physical activity, food choice, and weight management goals and practices among US college students. Am J Prev Med. 2000 Jan;18(1):18-27.

[7] Krishnan RP, Ramani P, Sherlin HJ, Sukumaran G, Ramasubramanian A, Jayaraj G, et al. Surgical Specimen Handover from Operation Theater to Laboratory: A Survey. Ann Maxillofac Surg. 2018 Jul;8(2):234-8.

[8] Palati S, Ramani P, Sherlin HJ, Gheena S, Don KR, Jayaraj G, et al.
Age Estimation of an Individual Using Olze's Method in Indian Population-A Cross-Sectional Study. Indian $\mathbf{J}$ Forensic Med Toxicol. 2019;13(3):121-4.

[9] Hannah R, Ramani P, Sherlin HJ, Ranjith G, Ramasubramanian A, Jayaraj G, et al. Awareness about the use, ethics and scope of dental photography among undergraduate dental students dentist behind the lens. Research Journal of Pharmacy and Technology. 2018;11(3):10126.

[10] Gunasekaran G, Abilasha R. Tooth Sensitivity Among Residential University Students In Chennai [Internet]. Asian Journal of Pharmaceutical and Clinical Research. 2016. p. 63. Available from:

http://dx.doi.org/10.22159/ajpcr.20 $16 . v 9 s 2.13228$

[11] Sarbeen JI, Gheena S. Microbial variation in climatic change and its effect on human health. Research Journal of Pharmacy and Technology. 2016;9(10):1777-81.

[12] Harrita S, Santhanam A. Determination of Physical Height Using Clinical Crown Height of Deciduous Teeth. Indian $\mathrm{J}$ Forensic Med Toxicol. 
2019;13(4):23-7.

[13] Ahad M, Gheena S. Awareness, attitude and knowledge about evidence based dentistry among the dental practitioner in Chennai city. Research Journal of Pharmacy and Technology. 2016;9(11):1863-6.

[14] Padavala S, Sukumaran G. Molar Incisor Hypomineralization and Its Prevalence. Contemp Clin Dent. 2018 Sep;9(Suppl 2):S246-50.

[15] Manohar J, Abilasha R. A Study on the Knowledge of Causes and Prevalance of Pigmentation of Gingiva among Dental Students. Indian Journal of Public Health Research \& Development. 2019;10(8):95-100.

[16] Sheriff K, Santhanam A. Knowledge and Awareness towards Oral Biopsy among Students of Saveetha Dental College. Research Journal of Pharmacy and Technology. 2018;11(2):543-6.

[17] Guru PE, Gheena S. A study of empathy across students from 4 health disciplines among 1st years and Final years. Research Journal of Pharmacy and Technology. 2016;9(9):1472.

[18] Palati S, Ramani P, Shrelin HJ,
Sukumaran G, Ramasubramanian A, Don KR, et al. Knowledge, Attitude and practice survey on the perspective of oral lesions and dental health in geriatric patients residing in old age homes. Indian J Dent Res. 2020 Jan;31(1):22-5.

[19] Abitha T, Santhanam A. Correlation between bizygomatic and maxillary central incisor width for gender identification. Brazilian Dental Science. 2019 Oct 31;22(4):458-66.

[20] Uma PK, Ramani P, Sherlin HJ, Others. Knowledge about Legal Aspects of Medical Negligence in India among Dentists--A Questionnaire Survey. Medico Legal Update. 2020;20(1):111-5.

[21] Shree KH, Hema Shree K, Ramani P, Herald Sherlin, Sukumaran G, Jeyaraj G, et al. Saliva as a Diagnostic Tool in Oral Squamous Cell Carcinoma - a Systematic Review with Meta Analysis [Internet]. Vol. 25, Pathology \& Oncology Research. 2019. p. 44753. Available from: http://dx.doi.org/10.1007/s12253019-00588-2

[22] Boreham C, Riddoch C. The physical activity, fitness and health of children. J Sports Sci. 2001 
Dec;19(12):915-29.

[23] Warburton DER, Nicol CW, Bredin SSD. Health benefits of physical activity: the evidence. CMAJ. 2006 Mar 14;174(6):8019.

[24] Caspersen CJ, Pereira MA, Curran KM. Changes in physical activity patterns in the United States, by sex and cross-sectional age. Med Sci Sports Exerc. 2000 Sep;32(9):1601-9.

[25] Calestine J, Bopp M, Bopp CM, Papalia Z. College Student Work Habits are Related to Physical Activity and Fitness. Int $\mathrm{J}$ Exerc Sci. 2017 Nov 1;10(7):1009-17.

[26] Van Dyck D, De Bourdeaudhuij I, Deliens T, Deforche B. Can changes in psychosocial factors and residency explain the decrease in physical activity during the transition from high school to college or university? Int J Behav Med. 2015 Apr;22(2):178-86.

[27] Jung SI, Serralta FB, Nunes MLT, Eizirik CL. Beginning and end of treatment of patients who dropped out of psychoanalytic psychotherapy. Trends Psychiatry Psychother. 2013;35(3):181-90. 